FINAL REPORT

U.S. Department of Energy

\title{
SETTLING OF SPINEL IN A HIGH-LEVEL WASTE GLASS MELTER
}

Principal Investigator: Pavel Hrma

Institution: Pacific Northwest National Laboratory, Richland, Washington

Principal Co-Investigator: Pert Schill

Institution: Glass Service, Inc., Vsetin, Czech Republic

Collaborator: Lubomir Nemec

Institution: Academy of Sciences of the Czech Republic, Prague, Czech Republic

Project Number: $\mathbf{6 5 4 2 2}$

Grant Number: Contract DE-AC06-76RL01830

Grant Project Officers: N/A

Project Duration: 9/1998 - 9/2001 


\section{Table of Contents}

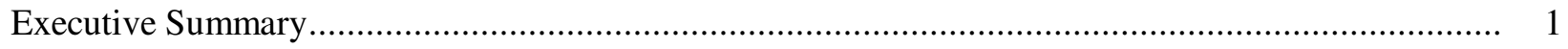

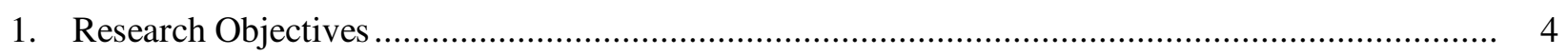

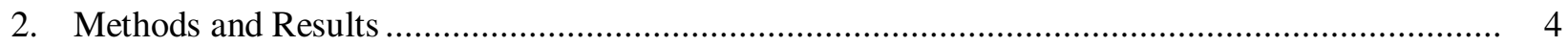

3. Relevance, Impact, and Technology Transfer ................................................................. 9

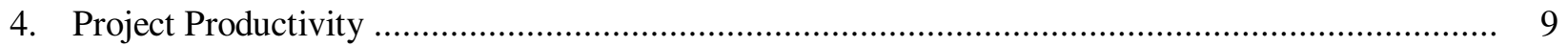

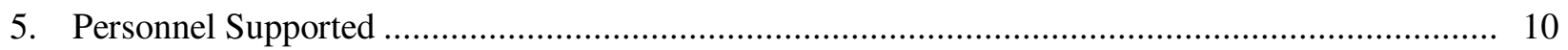

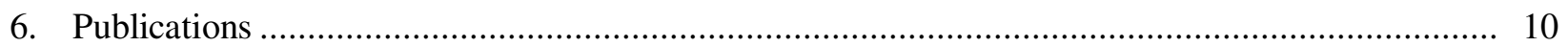

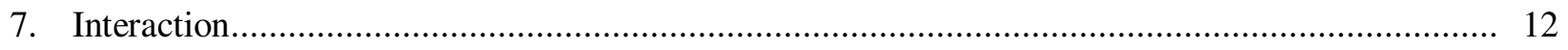

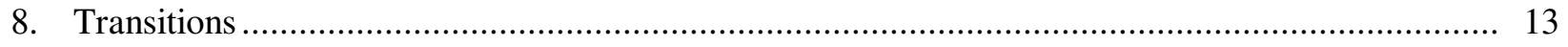

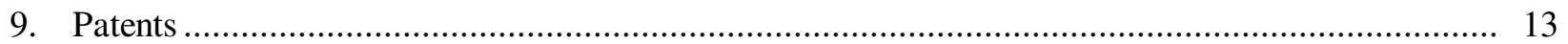

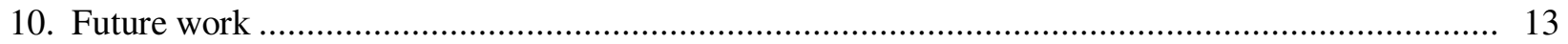

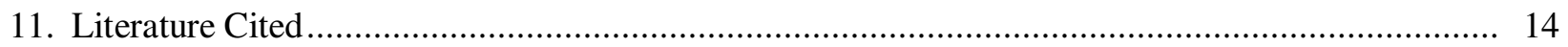

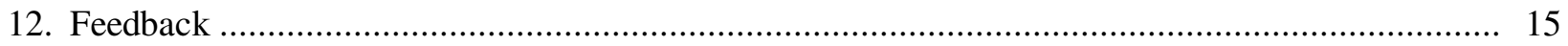

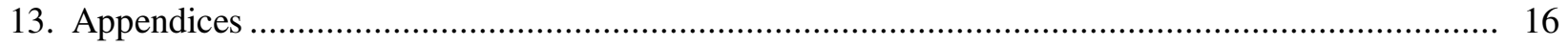

Appendix A: Modeling of Spinel Settling in Waste Glass Melter ....................................... 16

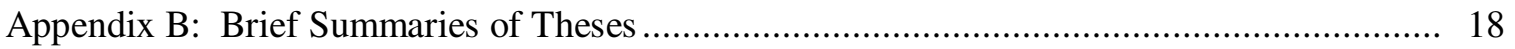

Appendix C: Spinel Crystallization in Borosilicate Glasses for Radioactive Waste Disposal ... 28

\section{Figures}

1. Equilibrium Mass Fraction of Spinel in MS-7 Glass as a Function of Temperature.

2. $T_{L}$ as a Function of Mass Fraction of a Component Added to (or removed from) MS-7

Glass (baseline) [4]; $\Delta g_{i}=g_{i}$ (glass) $-g_{i}$ (baseline); $g_{i}$ is the $i$-th Component Mass Fraction ............. 6

3. $T_{L}$ of MS-7 Glass as a Function of $p_{\mathrm{O} 2}$ Atomic $\%$ Elements in Spinel .......................................... 6

4. Atomic \% Elements in Spinel

5. Spinel Crystal Number Density $\left(n_{s}\right)$ as Function of Temperature for MS-7 Glass Without

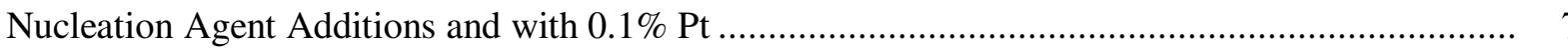

6. Spinel Crystal Number Density $\left(n_{s}\right)$ as a Function of Minor Component Addition ......................... 7 
7. Spinel Crystals in HLW Glass (clockwise from top left): A Scanning Electron Microscopy (SEM) Image of an Octahedral Crystal Isolated from Glass by Acid Digestion; a Large (approximately $20 \mu \mathrm{m}$ ) Spinel Crystal in Transmitted Light ............................................... 7

8. Sludge Layer Thickness (standard case) ........................................................................ 8

\section{Tables}

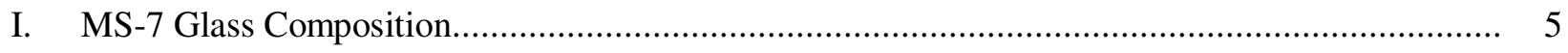

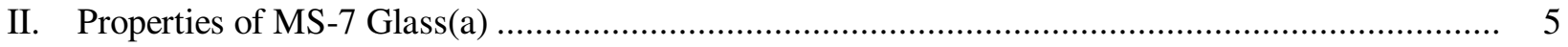

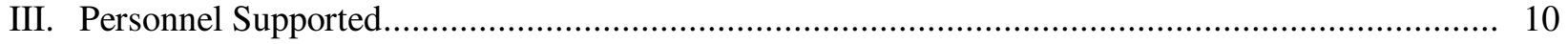

IV. Papers Published in Peer-Reviewed Journal and Proceedings ................................................. 10

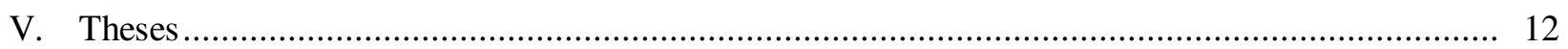

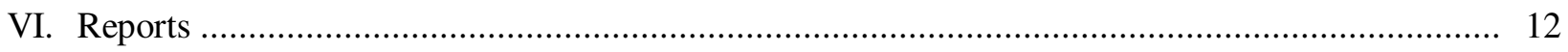

VII. Papers Accepted or Submitted for Publication ................................................................... 12 


\section{Executive Summary}

High-level nuclear waste is being vitrified, i.e., converted to a durable glass that can be stored in a safe repository for hundreds of thousands of years. Waste vitrification is accomplished in reactors called melters to which the waste is charged together with glass-forming additives. The mixture is electrically heated to a temperature as high as $1150^{\circ} \mathrm{C}$ (or even higher in advanced melters) to create a melt that becomes glass on cooling. This process is slow and expensive. Moreover, the melters that are currently in use or are going to be used in the U.S. are sensitive to clogging and thus cannot process melt in which solid particles are suspended. These particles settle and gradually accumulate on the melter bottom. Such particles, most often small crystals of spinel (a mineral containing iron, nickel, chromium, and other minor oxides), inevitably occur in the melt when the content of the waste in the glass (called waste loading) increases above a certain limit. To avoid the presence of solid particles in the melter, the waste loading is kept rather low, in average $15 \%$ lower than in glass formulated for more robust melters.

How do we know the melter-friendly level of the waste loading for a particular waste composition? Historically, this level was determined using the following rule of thumb: If the highest temperature at which crystals can coexist with the glass at equilibrium (called liquidus) is lower than $1050^{\circ} \mathrm{C}$, the glass was considered risk-free for the currently used melters. The goal of this EMSP-funded project was to determine how good this rule of thumb is.

To achieve this goal, a special glass was developed that represents a typical waste glass to be produced at Hanford and is easy to handle in the laboratory. The formation of spinel crystals in that glass was examined in great detail. We measured how many crystals are formed in per unit volume of glass, how large they are, what their composition is, how rapidly they grow or dissolve, and how quickly they settle to form sludge. These measurements were carried out at various temperatures. In some cases, atmospheres of different oxygen concentrations were used to simulate a range of possible melter 
conditions. The melting process itself, that is, the details of how the mixture of waste and glass-forming additives become glass upon heating, was also carefully examined to trace the origins of spinel crystallization. The results of these measurements were evaluated and mathematically formulated. This was an important step that allowed these expressions to be incorporated into mathematical models that simulate the heat and mass flow in the melter.

Mathematical models for the glass-melting process have been developed since the 1960s and improved ever since. However, only this EMSP project extended these models to simulate the behavior of solid particles, such as spinel, in waste-glass melters. The original intention was to calculate the rate at which spinel settles at the melter bottom and how rapidly the sludge layer grows. This goal was achieved. It was confirmed that the main factor that controls the rate of growth of the sludge layer is the size of crystals. Experiments have revealed that crystals grow small in the presence of noble metals in the waste. Because noble metals are common minor components of high-level wastes, the control of crystal size should not be difficult.

Some results of model calculations were, however, unexpected. The early calculations showed that the melter can mix the melt extremely well. The surprising consequence of this advantage became clear only in the last year of the project, when all measurements were completed and a model parameter study was finished. The commonly held assumption was that crystals, if they form at all, should dissolve easily in the melter because of the liquidus constraint which guaranteed that the melt temperature was above liquidus in most of the melt volume. This, as the calculation showed, was not the case. The melt circulates within the melter between cool and hot regions so fast that crystals do not have a sufficient time to dissolve while in the hot zone. As a result, some steady-state size and concentration of crystals is established. An interesting consequence of this situation is that the liquidus temperature has little effect on crystal settling; its effect is much smaller than the effect of crystal size. At least for the melter 
simulated by the model, the liquidus temperature could be $100^{\circ} \mathrm{C}$ above the accepted constraint without a serious impact on melter performance.

These results are potentially of a crucial consequence on nuclear waste vitrification. These results suggest that even in the currently used melters that are sensitive to settling, the waste loading could increase without putting the melters at unacceptable risk, provided that the crystal size is kept small. Consequently, a great saving of the vitrification and disposal cost is possible without a change in melter or plant design.

Melters for nuclear waste glass have been developed and tested over the last 40 years, and the liquidus constraint was taken for granted over most of this period. This EMSP project brought understanding of the melting process to a level at which a substantial progress in waste-glass melting technology is possible. This happened over a short period of 3 years by the collaborative effort of a team of four institutes: Pacific Northwest National Laboratory (PNNL) and three institutes based in the Czech Republic-Glass Service (GS), Inc., Institute of Inorganic Chemistry (IIC) at the Academy of Sciences of the Czech republic, and the Institute of Chemical Technology (ICT), Prague. Experimental data were produced at PNNL, IIC, and ICT. Models were developed at GS and IIC. The research produced nearly 30 publications, including two M.S. and one Ph.D. theses. The summaries of these theses are appended to this report. 


\section{Research Objectives}

The research on spinel settling in the high-level waste (HLW) glass melter was conducted to assist HLW retrieval, glass formulation, feed preparation, and melter design and operation for minimum-risk and minimum-cost vitrification of HLW at Hanford and other DOE sites. The main risk for the continuous operation HLW glass melters is accumulation of solid phases, such as noble metals, spinel, eskolaite, or zirconium-containing minerals. To lower this risk, HLW glass is currently formulated with low liquidus temperature $\left(T_{L}\right)$, nominally below $1050^{\circ} \mathrm{C}$ (but typically, because of uncertainties, below $950^{\circ} \mathrm{C}$ ), which is achieved by decreasing the waste loading in glass until the $T_{L}$ is sufficiently decreased. Low waste loading, in turn, means a high volume of waste glass, and thus high capital, production, and disposal costs.

The Tanks Focus Area (TFA) projects addressed the waste-loading problem by optimizing glass composition, including the $T_{L}$, to achieve maximum waste loading compatible with glass property constraints [1]. The constraint that most limits the waste loading in the majority of HLW streams is the $T_{L}$ constraint. Without this constraint, the waste-glass volume could decrease by 12 to $16 \%$ [1], which for Hanford represents several billons U.S. dollars.

Interestingly, no solid scientific basis exists for the $T_{L}$ constraint. This constraint is based on the assumption that if $T_{L}$ is lower than the estimated glass temperature in the melter, spinel or other crystals (except noble metals) would not be present within the melter, and thus the only problem to deal with would be the settling of noble metals. The lowest temperature of glass in the melter was estimated $100^{\circ} \mathrm{C}$ below the melter-operation temperature $\left(1150^{\circ} \mathrm{C}\right)$. However, the true minimum temperature is that in the melting zone below the cold cap, where the melt temperature is as low as $850^{\circ} \mathrm{C}$, and hence spinel or other crystalline phases will still exist in this region. It was assumed that these crystals would dissolve as soon as the glass reaches a temperature above the $T_{L}$.

The purpose of this EMSP project was to clarify the assumptions regarding spinel behavior in the HLW glass melter through developing a basic understanding of the dynamics of spinel nucleation, growth, and dissolution in the velocity, temperature, and redox fields that exist in the glass-melting process. This task was approached by conducting an experimental study of spinel formation and settling in molten glass in conjunction with developing a mathematical tool for predicting the spinel behavior and spinel accumulation rate in the melter.

The research was a collaborative effort of four institutions, the Pacific Northwest National Laboratory (Richland, Washington), the Academy of Sciences of the Czech Republic (Prague), the Glass Service, Inc. (Vsetin, Czech Republic), and the Institute of Chemical Technology (Prague). Several tasks were performed jointly with the TFA program. The results were presented at waste management and other scientific conferences, published in conference proceedings and scientific journals, and presented to end users (such as Duratek) at Hanford. Based on the success of the spinel study, the Duratek Company established a contract with Glass Service, Inc. to study the settling of solids in their HLW glass melters.

\section{Methods and Results}

Experimental studies were all conducted with MS-7 glass (Table I), an 11-componet generic HLW glass that formed spinel as the primary crystalline phase with $T_{L}=1078^{\circ} \mathrm{C}$. The physical properties of the 
glass that were needed for mathematical modeling (density, viscosity, and electrical conductivity) were measured as functions of temperature (Table II). To measure the density of spinel, spinel crystals were isolated from the glass by dissolving glass in an acid.

Table I. MS-7 Glass Composition

\begin{tabular}{|c|c|c|c|c|c|}
\hline Oxide & Mass Fraction & Oxide & Mass Fraction & Oxide & Mass Fraction \\
\hline $\mathrm{Al}_{2} \mathrm{O}_{3}$ & 0.0800 & $\mathrm{Li}_{2} \mathrm{O}$ & 0.0454 & $\mathrm{NiO}$ & 0.0095 \\
\hline $\mathrm{B}_{2} \mathrm{O}_{3}$ & 0.0700 & $\mathrm{MgO}$ & 0.0060 & $\mathrm{SiO}_{2}$ & 0.4531 \\
\hline $\mathrm{Cr}_{2} \mathrm{O}_{3}$ & 0.0030 & $\mathrm{MnO}$ & 0.0050 & $\mathrm{ZrO}_{2}$ & 0.0600 \\
\hline $\mathrm{Fe}_{2} \mathrm{O}_{3}$ & 0.1150 & $\mathrm{Na}_{2} \mathrm{O}$ & 0.1530 & & \\
\hline
\end{tabular}

Table II. Properties of MS-7 Glass ${ }^{(a)}$

\begin{tabular}{|l|l|l|l||}
\hline Property & Symbol & Unit & Equation or Value \\
\hline Viscosity & $\eta$ & $\mathrm{Pa} \cdot \mathrm{s}$ & $\exp (-12.3+19723 / T)$ \\
\hline Electrical Conductivity & $\sigma$ & $\mathrm{S} \cdot \mathrm{m}^{-1}$ & $\exp (6.97-2914 /(T-466))$ \\
\hline Specific Heat & $\mathrm{c}_{\mathrm{p}}$ & $\mathrm{J} \cdot \mathrm{kg}^{-1} \cdot \mathrm{K}^{-1}$ & 1350 \\
\hline Melt Density & $\rho_{g}$ & $\mathrm{~kg} \cdot \mathrm{m}^{-3}$ & $2722.65-0.2077 T$ \\
\hline Spinel Density & $\rho_{s}$ & $\mathrm{~kg} \cdot \mathrm{m}^{-3}$ & 5140 \\
\hline Liquidus Temperature & $T_{L}$ & ${ }^{\circ} \mathrm{C}$ & 1078 \\
\hline $\begin{array}{l}\text { Spinel Equilibrium } \\
\text { Fraction }\end{array}$ & $C$ & & $0.0825\left\{1-\exp \left[-5110.7\left(1 / T-1 / T_{L}\right)\right]\right\}$ \\
\hline $\begin{array}{l}\text { Mass Transfer Coefficient } \\
k_{H}\end{array}$ & $k_{\text {hind }}$ & $\mathrm{m} \cdot \mathrm{s}^{-1}$ & $\exp (-2.95459-15708 / T)$ \\
\hline $\begin{array}{l}\text { Hindered Settling } \\
\text { Coefficient }\end{array}$ & 0.19 \\
\hline \begin{tabular}{l} 
(a) Adopted from [2]; data validity range is from $850^{\circ} \mathrm{C}$ to $1200^{\circ} \mathrm{C}$ \\
\hline
\end{tabular}
\end{tabular}

The equilibrium fraction of spinel in MS-7 glass was measured using quantitative X-ray diffraction (XRD) as a function of temperature, glass composition (adding to or removing components from the MS7 baseline), and the partial pressure of oxygen $\left(p_{O 2}\right)$, see Figures 1 to 3. Spinel composition was also measured as a function of temperature (Figure 4) and $p_{O 2}$. The $p_{O 2}$ is an important parameter for the HLW glass melting process because it affects both foaming and spinel precipitation in the melter.

The main focus of the experimental study was on kinetics, that is, the measurements of the rates of nucleation, crystal growth, and crystal dissolution [7]. It was discovered early on that spinel nucleation proceeds nearly instantaneously [8]. Moreover, the feed melting studies revealed that tiny (submicron) spinel crystals precipitate already from the primary (nitrate) melt [9]. These low-chromium crystals dissolved as the conversion progressed, but could also survive as seeds for crystals that form in the glass. 


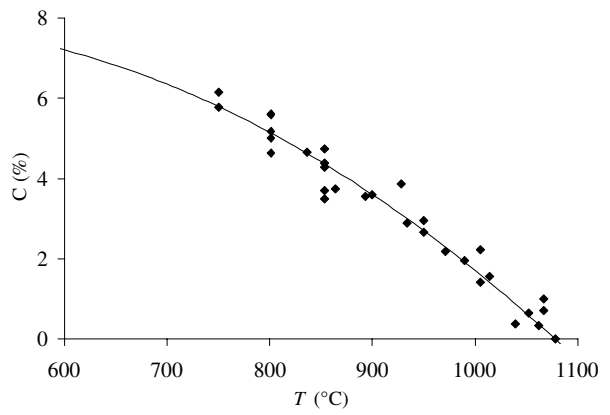

Figure 1. Equilibrium Mass Fraction of Spinel in MS-7 Glass as a Function of Temperature [3]

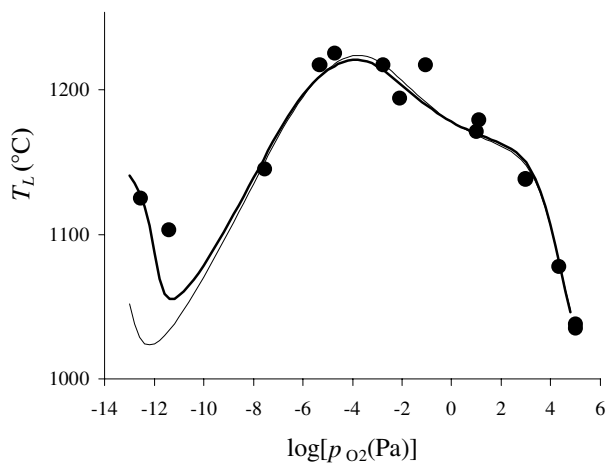

Figure 3. $T_{L}$ of MS-7 Glass as a Function of $p_{\mathrm{O} 2}[5]$

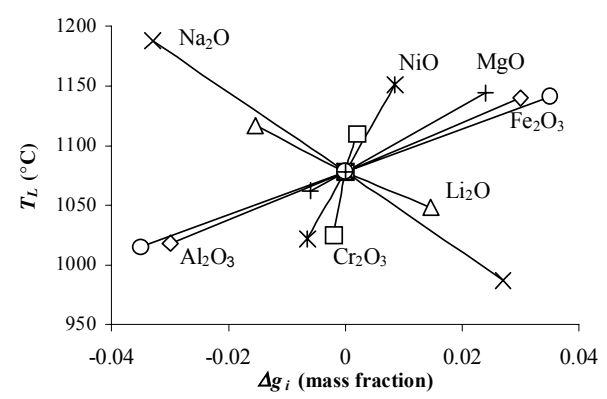

Figure 2. $T_{L}$ as a Function of Mass Fraction of a Component Added to (or removed from) MS-7 Glass (baseline) [4]; $\Delta g_{i}=g_{i}($ glass $)-g_{i}$ (baseline); $g_{i}$ is the $i$-th Component Mass Fraction

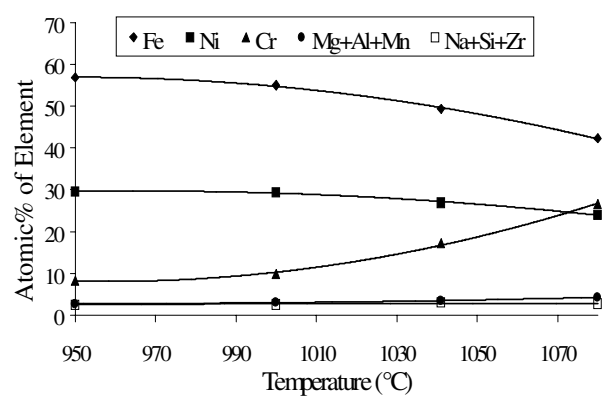

Figure 4. Atomic \% Elements in Spinel [6]

The rate of nucleation was measured by counting the number of crystals per unit volume of glass. For the MS-7 baseline glass, the number of nuclei was low at the glass-processing-temperature range, and strongly increased with decreasing temperature (Figure 5). The surface nucleation dominated when crushed glass was heated from the room temperature on [6]. The number density at the glass-processing temperature interval increased up to 4 orders of magnitude when nucleation agents were added to the glass as minor components (Figure 6). The most effective agents were noble metals. The addition of noble metals resulted in at least a tenfold decrease in the crystal size, and hence at least a hundredfold decrease in the rate of crystal settling.

The rate of crystal growth and dissolution was determined by measuring crystal size in thin sections of quenched glass samples (Figure 7) that were isothermally heat treated.

A special methodology was developed for the settling-rate study to eliminate all possible sources of convection, such as bubbles and surface forces [12]. The measured Stokes coefficient was only slightly different from that for hindered settling of cubic particles in room-temperature liquids [13]. Finally the density of spinel sludge was determined both in laboratory crucibles and in a sample taken from a pilotscale melter [14]. 


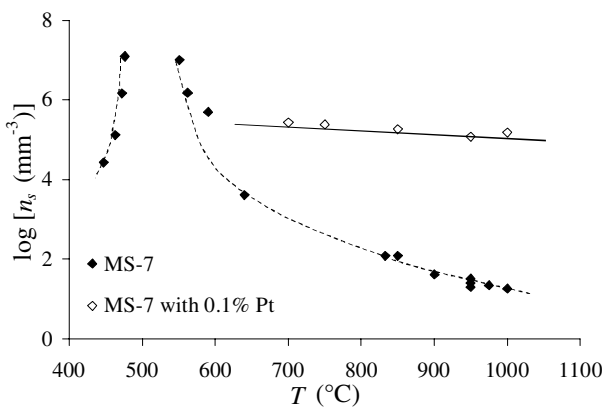

Figure 5. Spinel Crystal Number Density $\left(n_{s}\right)$ as Function of Temperature for MS-7 Glass Without Nucleation Agent Additions and with $0.1 \% \mathrm{Pt}$ [2]
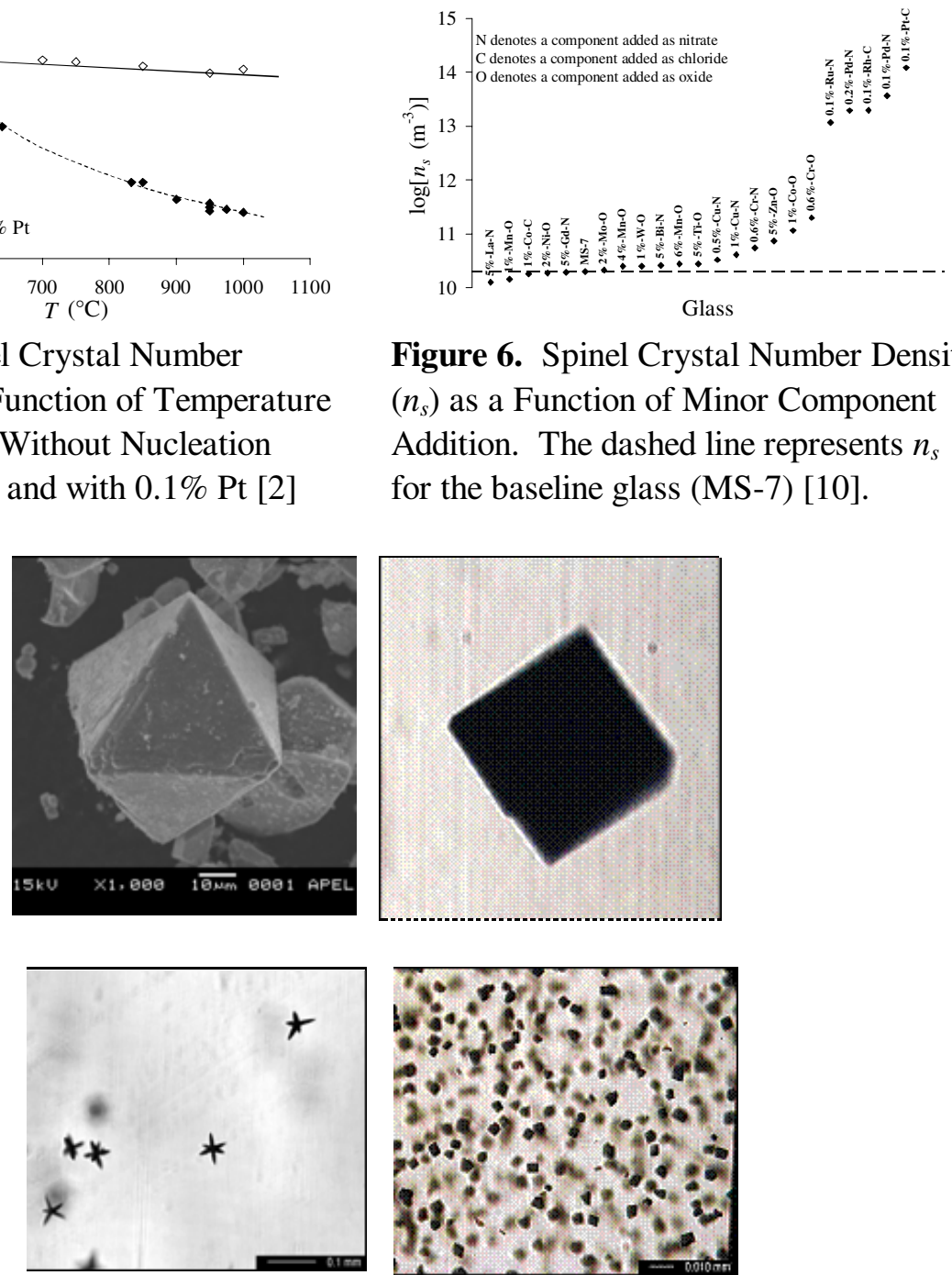

Figure 6. Spinel Crystal Number Density $\left(n_{s}\right)$ as a Function of Minor Component Addition. The dashed line represents $n_{s}$ for the baseline glass (MS-7) [10].

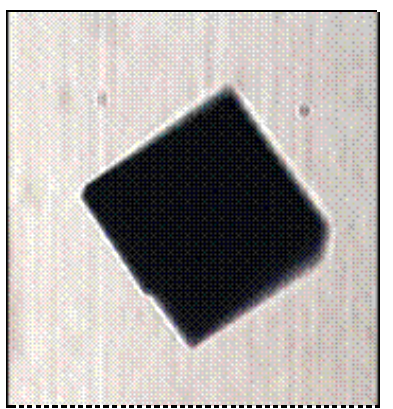

Figure 7. Spinel Crystals in HLW Glass (clockwise from top left): A Scanning Electron Microscopy (SEM) Image of an Octahedral Crystal Isolated from Glass by Acid Digestion; a Large (approximately $20 \mu \mathrm{m}$ ) Spinel Crystal in Transmitted Light [11]

For the purpose of mathematical modeling, it was necessary to formulate constitutive equations for spinel-glass-mixture equilibrium and kinetic behavior as functions of melt temperature. The rate of spinel crystal growth and dissolution was represented by the Hixson-Crowell equation in the form [7]

$$
\frac{d a}{d t}=2 k_{H}\left(C_{0}-C\right)
$$


where $a$ is the crystal size, $C_{0}$ is the equilibrium solid-spinel mass fraction, $C$ is the solid-spinel mass fraction, and $k_{H}$ is the mass-transfer coefficient. The mass-transfer coefficient varied with temperature according to the Arrhenius relationship shown in Table II. The Kolmogorov-Mehl-Johnson-Avrami equation was also fitted to crystal-growth data at early stages when the sinking motion has not been fully established [15].

The current mathematical model for the glass-making furnace was first applied to the selected HLW glass melter (the West Valley type) for a crystal-free glass. The results showed that the melter produced a rather vigorous circular flow, assuring a good mixing and homogenizing the melt. In the following stage, the model was augmented by introducing the field of crystal (spinel) concentration [16]. Crystals were allowed to grow or dissolve according to Equation (1) and settle following the Stokes law (modified for hindered settling). The tricky problem of the motion of crystals of different sizes with different velocities was successfully solved. The results showed that spinel was nearly uniformly dispersed throughout the volume of the melt in the melter [17]. Hence, the melter operated as a nearly ideal mixer (see Appendix C).

The rate of growth of the sludge layer was obtained as a function of the position in the melter [18]. The outcome of the calculation showed that the settling rate was rather low, $0.04 \mathrm{~mm} /$ year (see Figure 8), even though the $T_{L}$ was nearly $30^{\circ} \mathrm{C}$ above the maximum allowable value. The results of the parametric study (Appendix $\mathrm{C}$ ) showed that $T_{L}$ had little effect on the rate of the sludge-layer growth. When the $T_{L}$ increased from $1078^{\circ} \mathrm{C}$ to $1128^{\circ} \mathrm{C}$, the rate of growth increased from $0.04 \mathrm{~mm} /$ year to $0.09 \mathrm{~mm} /$ year (for $1-\mu \mathrm{m}$ crystals). The crystal size had a much greater impact on the sludge-layer growth rate. When the crystal size increased from $1 \mu \mathrm{m}$ to $5 \mu \mathrm{m}$, the sludge-layer growth rate increased from $0.04 \mathrm{~mm} / \mathrm{year}$ to $2 \mathrm{~mm} /$ year (for $T_{L}=1078^{\circ} \mathrm{C}$ ).

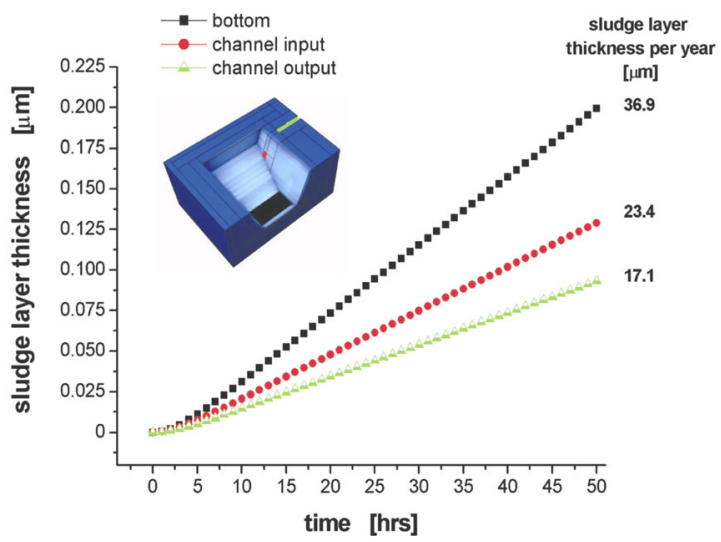

Figure 8. Sludge Layer Thickness (standard case)

The model can be potentially extended to incorporate the oxidation-reduction equilibrium and the concentration and sizes (including rates of growth) of gas bubbles. Melter idling can also be simulated. The model can be used by testing different melter designs, the effect of bubbling, and the impact of glass composition on spinel settling. Thus, melter design, melter operation, and glass formulation can be optimized. 


\section{Relevance, Impact, and Technology Transfer}

As explained above, the new scientific knowledge gained in this EMSP project is fully focused on a critical DOE environmental-management problem, the vitrification of HLW. The new scientific knowledge that has been generated by this project potentially improves the vitrification technology and HLW cleanup by allowing, through an increased waste loading, a significant reduction in future costs, schedules, and risks while meeting the DOE compliance requirements. This has been accomplished by bridging the gap between broad fundamental research (based on the physical chemistry of glass crystallization and mathematical modeling of complex physical fields) and the applied technology of HLW glass melting.

The project's impact on individuals, laboratories, departments, and institutions has been remarkable. A dozen students had an opportunity to learn experimental skills, conduct scientific investigation, evaluate and interpret the results, and present and published the findings. New procedures have been developed for studies of glass-melting chemistry, molten-glass redox, and glass crystallization. For example, the Avrami model has been improved by introducing the temperature-dependence of the equilibrium state of the glass-crystal mixture and using this model as a rigorous rate equation (in the differential form) $[11,15]$. The results will be used not only for vitrification-technology improvement, but also for future studies of the glass-melting process both at PNNL and the collaborating institutes. For example, Duratek, Inc., a company responsible for waste-glass melter design at Hanford, is working with Glass Service, Inc. to model the settling of solids in the HLW glass melters.

Larger scale trials will inevitably follow because reducing the vitrification cost is a high DOE priority. Vitrifying HLW without the $T_{L}$ constraint can save 12 to $16 \%$ of the glass volume produced at Hanford [1], which translates to several billions of U.S. dollars. Also, the Glass Development Laboratory at PNNL has developed a new capacity and an expertise for glass-melting research. Several glass-melting companies showed an interest in helping them with their problems. Three minor projects have currently been commissioned.

As stated above, this research advanced our understanding in the area of glass processing and the physical chemistry of glass, especially glass crystallization. About 30 reports and papers have been completed and have been published or are in the review process. However, several hurdles still exist that must be overcome before the results of this project can be successfully applied to DOE Environmental Management problems. One is a better understanding of the distribution of partial pressures of gases within the melter and their impact on bubble formation and crystal nucleation. Another task is the effect of glass composition on crystallization kinetics; this would allow an efficient glass optimization. These are just two examples of several problems that should be addressed (see Section 10 for a more complete discussion).

\section{Project Productivity}

The project accomplished all of the proposed goals and achieved additional benefits that were not anticipated initially. The project not only accomplished the goal to predict, using mathematical model, the rate of settling of crystalline phases in a HLW melter, but also showed that the current understanding was incomplete and unnecessarily restrictive to waste loading in HLW glass at a very high cost. The project was finished on schedule, but was several times behind schedule during its 3-year duration, which was necessitated by unexpected experimental difficulties. The initial work plan was never revised, 
though a lot of extra work was accomplished because a research group of enthusiastic students allowed an efficient usage of the budget and time.

\section{Personnel Supported}

The list of professional personnel supported by and/or associated with the research effort is in Table III (arranged alphabetically and according to the affiliations).

Table III. Personnel Supported

\begin{tabular}{|c|c|c|c|c|}
\hline PNNL & IIC & ICT & GS & Other \\
\hline B. W. Arey ${ }^{(\mathrm{d})}$ & M. Jiricka ${ }^{(\mathrm{c})}$ & P. Izak $^{(c)}$ & A. Franek ${ }^{(d)}$ & J. Alton ${ }^{(\mathrm{b})}$ \\
\hline J. V. Crum ${ }^{(\mathrm{d})}$ & J. Klouzek ${ }^{(\mathrm{e})}$ & A. Jiricka ${ }^{(\mathrm{c})}$ & P. Schill ${ }^{(\mathrm{d})}$ & G. M. Irwin ${ }^{(a)}$ \\
\hline P. Hrma ${ }^{(\mathrm{d})}$ & J. Matyas ${ }^{(c)}$ & M. Mika ${ }^{(a)}$ & M. Trochta ${ }^{(\mathrm{d})}$ & T. J. Plaisted ${ }^{(\mathrm{b})}$ \\
\hline H. $\mathrm{Li}^{(\mathrm{d})}$ & L. Nemec ${ }^{(d)}$ & M. Patek ${ }^{(b)}$ & P. Viktorin ${ }^{(\mathrm{d})}$ & B. K. Wilson ${ }^{(\mathrm{b})}$ \\
\hline G. F. Piepel ${ }^{(\mathrm{d})}$ & & O. Št'áhlavský( ${ }^{(b)}$ & & C. Young ${ }^{(\mathrm{b})}$ \\
\hline M. J. Schweiger ${ }^{(d)}$ & & & & \\
\hline M.-L. Thomas ${ }^{(\mathrm{d})}$ & & & & \\
\hline J. D. Vienna ${ }^{(\mathrm{c}, \mathrm{d})}$ & & & & \\
\hline J. S. Young ${ }^{(\mathrm{d})}$ & & & & \\
\hline $\begin{array}{l}{ }^{(a)} \text { faculty, }{ }^{(b)} \text { student, } \\
\text { Acronyms: PNNL = P } \\
\text { of Sciences of the Cze } \\
\text { "Other" involves diff }\end{array}$ & $\begin{array}{l}\text { uate student, } \\
\text { c Northwest Nat }\end{array}$ & $\begin{array}{l}\text { isiting scientist } \\
\text { aboratory, IIC = Ins } \\
\text { of Chemical Techr }\end{array}$ & $\begin{array}{l}\text { of Inorganic C } \\
\text {, Prague, GS C }\end{array}$ & $\begin{array}{l}\text { try at the Academy } \\
\text { Service, Inc.; }\end{array}$ \\
\hline
\end{tabular}

\section{Publications}

Publications that were fully or partly generated from the research effort funded by the EMSP project are listed in Tables IV through VII.

Table IV. Papers Published in Peer-Reviewed Journal and Proceedings

\begin{tabular}{|l|l|}
\hline \multicolumn{2}{|l|}{ Journals } \\
\hline 2000 & $\begin{array}{l}\text { M. Mika, P. Hrma, and M. J. Schweiger. "Rheology of Spinel Sludge in Molten Glass," } \\
\text { Ceramics-Silikaty 44, 86-90. }\end{array}$ \\
\hline 2001 & $\begin{array}{l}\text { J. Klouzek and A. Franek. "Modeling of Particle Settling in High-Viscosity Liquid," Ceramics- } \\
\text { Silikaty 45 (2) 70-75. }\end{array}$ \\
\cline { 2 - 3 } & $\begin{array}{l}\text { J. D. Vienna, P. Hrma, J. V. Crum, and M. Mika. "Liquidus Temperature-Composition Model for } \\
\text { Multi-Component Glasses in the Fe, Cr, Ni, and Mn Spinel Primary Phase Field," J. Non-Cryst. } \\
\text { Solids 292, 1-24. }\end{array}$ \\
\cline { 2 - 3 } & $\begin{array}{l}\text { P. Izak, P. Hrma, B. W. Arey, and T. J. Plaisted. "Effect of Batch Melting, Temperature History, } \\
\text { and Minor Component Addition on Spinel Crystallization in High-Level Waste Glass," J. Non- }\end{array}$ \\
\hline Pryst. Solids 289, 17-29. \\
\hline 1999 & $\begin{array}{l}\text { D. G. Casler and P. Hrma. "Nonisothermal Kinetics of Spinel Crystallization in a HLW Glass," } \\
\text { Mat. Res. Soc. Proc. 556, 255-262. }\end{array}$ \\
\cline { 2 - 3 } & $\begin{array}{l}\text { M. Mika, J. V. Crum, and P. Hrma. "Spinel Precipitation in High-Level Waste Glass," } \\
\text { Proceedings of the 5 } 5^{\text {th }} \text { ESG Conference, Prague, Czech Republic. }\end{array}$ \\
\hline
\end{tabular}




\begin{tabular}{|c|c|}
\hline \multirow[t]{6}{*}{2000} & $\begin{array}{l}\text { M. W. Stachnik, P. Hrma, and H. Li. "Effects of High-level Waste Glass Composition on Spinel } \\
\text { Precipitation," Ceram. Trans. 107, 123-130. }\end{array}$ \\
\hline & $\begin{array}{l}\text { P. Hrma, J. D. Vienna, J. V. Crum, G. F. Piepel, and M. Mika. "Liquidus Temperature of High- } \\
\text { Level Waste Borosilicate Glasses with Spinel Primary Phase," Mat. Res. Soc. Proc. 608, 671-676. }\end{array}$ \\
\hline & T. J. Plaisted, P. Hrma, J. Vienna, and A. Jiricka. “Liquidus Temperature and Primary \\
\hline & $\begin{array}{l}\text { Crystallization Phases in High-Zirconia High-Level Waste Borosilicate Glasses," Mat. Res. Soc. } \\
\text { Proc. 608, 709-714. }\end{array}$ \\
\hline & $\begin{array}{l}\text { J. Klouzek, and A. Franek. "Physical and Mathematical Modeling of Spinel Settling in High- } \\
\text { Level Waste Glass" Waste Management } 2000 \text { Tucson. Arizona. }\end{array}$ \\
\hline & $\begin{array}{l}\text { P. Hrma and J. D. Vienna. "Balancing Cost and Risk by Optimizing the High-Level Waste and } \\
\text { Low-Activity Waste Vitrification," Waste Management'00, University of Arizona, Tucson, } \\
\text { Arizona. }\end{array}$ \\
\hline \multirow[t]{12}{*}{2001} & $\begin{array}{l}\text { T. J. Plaisted, J. Alton, B. K. Wilson, and P. Hrma. "Effect of Minor Component Addition on } \\
\text { Spinel Crystallization in Simulated High-Level Waste Glass," Ceram. Trans. 119, 317-325. }\end{array}$ \\
\hline & $\begin{array}{l}\text { P. Izak, P. Hrma, and M. J. Schweiger. "Kinetics of Conversion of High-Level Waste to Glass," } \\
\text { ACS Symp. Series } 778,314-328 .\end{array}$ \\
\hline & $\begin{array}{l}\text { J. Klouzek, J. Alton, T.J. Plaisted, and P. Hrma. "Crucible Study of Spinel Settling in High-Level } \\
\text { Waste Glass," Ceram. Trans. 119, 301-308. }\end{array}$ \\
\hline & $\begin{array}{l}\text { P. Izak, P. Hrma, and J. Klouzek. "Evolution of Crystalline Phases during Feed-to-Glass } \\
\text { Conversion." Ceram. Trans. 119, 509-515 }\end{array}$ \\
\hline & $\begin{array}{l}\text { P. Izak, P. Hrma, B. K. Wilson, and J. D. Vienna. "Effect of Oxygen Partial Pressure on Liquidus } \\
\text { Temperature of a High-Level Waste Glass with Spinel Primary Phase," Ceram. Trans. 119, 309- } \\
316 .\end{array}$ \\
\hline & $\begin{array}{l}\text { T. J. Plaisted, F. Mo, B. K. Wilson, C. Young, and P. Hrma. "Surface Crystallization and } \\
\text { Composition of Spinel and Acmite in High-Level Waste Glass," Ceram. Trans. 119, 317-325. }\end{array}$ \\
\hline & $\begin{array}{l}\text { P. Schill, M. Trochta, J. Matyas, L. Nemec, and P. Hrma. "Mathematical Model of Spinel Settling } \\
\text { in a Real Waste Glass Melter," Waste Management Symposium 2001, Tucson, Arizona. }\end{array}$ \\
\hline & $\begin{array}{l}\text { J. Matyáš, J. Kloužek, L. Němec, and M. Trochta. "Spinel settling in HLW melters," ICEM'01 } \\
\text { The } 8^{\text {th }} \text { International Conference On Radioactive Waste Management and Environmental } \\
\text { Remediation, Bruges, Belgium. }\end{array}$ \\
\hline & $\begin{array}{l}\text { M. Mika, M. Patek, J. Maixner, S. Randakova, and P. Hrma. "The Effect of Temperature and } \\
\text { Composition on Spinel Concentration and Crystal Size in High-Level Waste Glass," ICEM'01 The } \\
8^{\text {th }} \text { International Conference On Radioactive Waste Management and Environmental Remediation, } \\
\text { Bruges, Belgium. }\end{array}$ \\
\hline & $\begin{array}{l}\text { P. Hrma and J. Alton. "Dissolution and Growth of Spinel Crystals in a High-Level Waste Glass," } \\
\text { ICEM'01 The } 8^{\text {th }} \text { International Conference On Radioactive Waste Management and } \\
\text { Environmental Remediation, Bruges, Belgium. }\end{array}$ \\
\hline & $\begin{array}{l}\text { J. Matyáš, L. Němec, J. Kloužek, M. Trochta. "The Influence of some Parameters on Spinel } \\
\text { Settling in HLW Melters," Proc. } 6^{\text {th }} \text { Int. Seminar on Mathematical Modeling of Glass Melting } \\
\text { Furnaces, June 28-29, Velké Karlovice, Czech Republic. }\end{array}$ \\
\hline & $\begin{array}{l}\text { P. Hrma, J. Alton, J. Klouzek, J. Matyas, M. Mika, L. Nemec, T. J. Plaisted, P. Schill, and M. } \\
\text { Trochta. "Increasing High-Level Waste Loading in Glass without Changing the Baseline Melter } \\
\text { Technology,” Waste Management ’01, University of Arizona, Tucson, Arizona. }\end{array}$ \\
\hline
\end{tabular}


Table V. Theses

\begin{tabular}{|l|l|}
\hline 2000 & $\begin{array}{l}\text { M. Patek. The Effect of Composition on the Equilibrium Concentration of Spinel in Glass, M.S. } \\
\text { Thesis, Institute of Chemical Technology, Prague, Czech Republic. }\end{array}$ \\
\hline 2001 & $\begin{array}{l}\text { O. Št'áhlavský. Crystallization of Compounds with Spinel Structure in Borosilicate Glasses for the } \\
\text { Disposal of Radioactive Wastes, M.S. Thesis, Institute of Chemical, Department of Glass and } \\
\text { Ceramics, Prague. }\end{array}$ \\
\cline { 2 - 2 } & $\begin{array}{l}\text { J. Matyáš. Description of the Behavior of Multitude Particles in Non-isothermal Convective } \\
\text { Melting Space, PhD. Thesis, Laboratory of Inorganic Materials, Prague, Czech Republic. }\end{array}$ \\
\hline
\end{tabular}

Table VI. Reports

1999 P. Hrma. "Modeling of Spinel Settling in Waste Glass Melter." In Science to Support DOE Site Cleanup, Pacific Northwest National Laboratory, PNNL-12208 UC-2000.

Table VII. Papers Accepted or Submitted for Publication

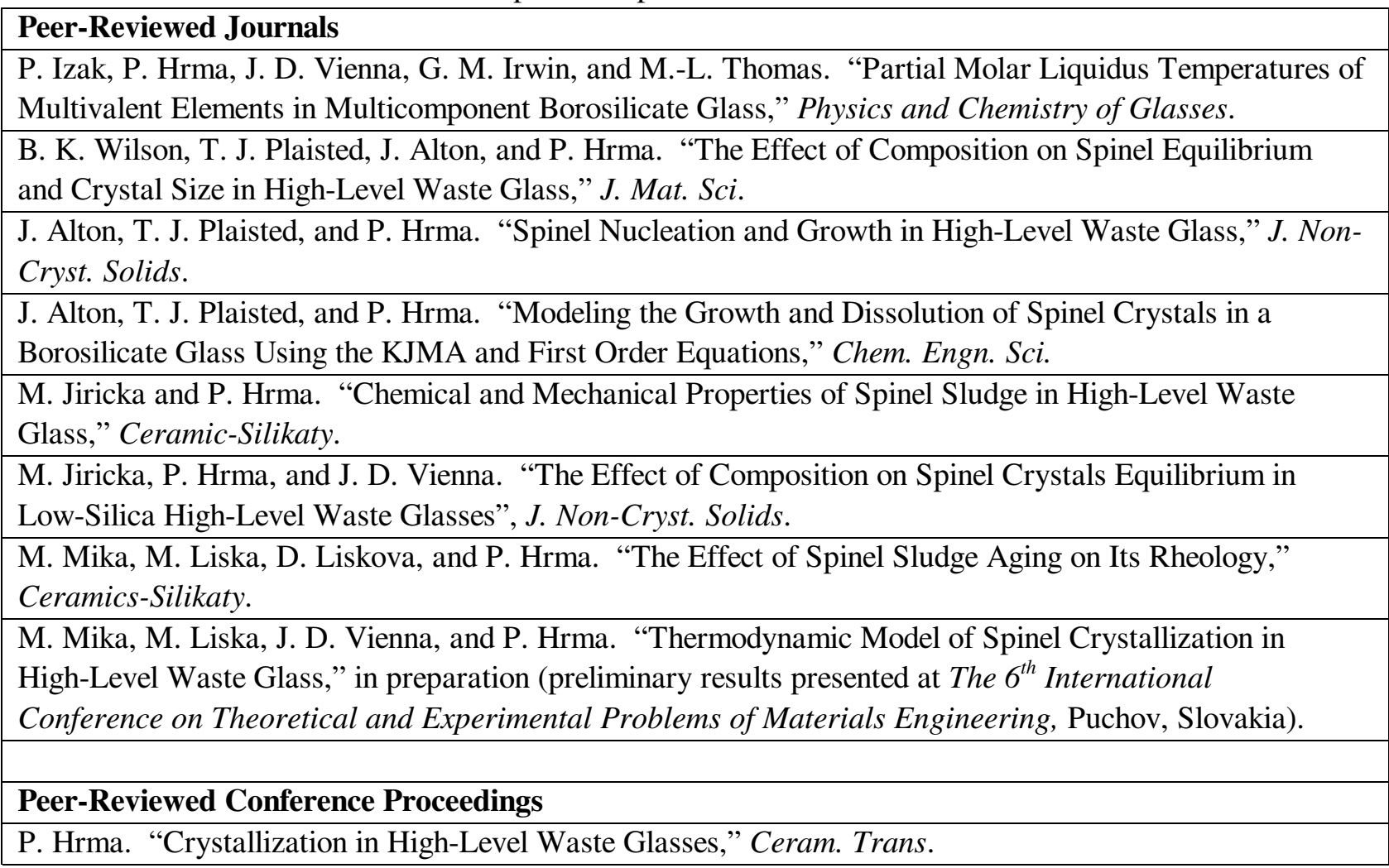

\section{Interaction}

The scientists involved in the project participated at many conferences and meetings, giving numerous presentations. We did not take records of these events unless papers were published in the proceedings. These publications are listed in Tables IV and VII. Two of the recent presentations from which no papers were published are the EMSP workshop that was held in Atlanta 2000, and the American Chemical Society Meeting held in Chicago in August 2001. M. Patek and O. Stahlavsky presented posters at ICT Student Conferences in 1999 and 2000. 
Consultative and advisory activity occurred at informal presentations and meetings to Numatec Hanford Company, British Nuclear Fuel Laboratory, Inc., and Duratek. Inc. The research was conducted and coordinated in collaboration with the DOE Tanks Focus Area Immobilization Program.

\section{Transitions}

The mathematical model developed on this project is currently being used for Duratek melters intended for vitrification of high-level and low-activity wastes at Hanford.

\section{Patents}

None.

\section{Future work}

A large amount of work has been done during the 3 years of this project. However, a lot more work is necessary for a successful implementation of the results. This has been proposed to EMSP as an extension of the current work (see Appendix A). What remains to be done? Briefly:

- More data are needed to determine the effect of glass composition on spinel behavior. This database is necessary for waste-glass formulation and melter operation.

- The effect of the redox state of the melt on spinel formation also needs more data. Controlling redox is one of the key elements in HLW vitrification.

- The interaction of spinel with noble metals has not been sufficiently understood, and yet this interaction plays a crucial role in the settling of both spinel and noble metals and the behavior of the sludge layer (a conductive sludge layer can ruin the melter).

- Mathematical models can optimize the melter-design parameters. A study is needed to determine the impact of these parameters on melter performance.

- The same is also true about the melter operating temperature and other conditions. A mathematical simulation can accelerate the development in this area and make it cost effective.

- The effect of melter idling on the settling of solids should be mathematically simulated to assess its effect on the settling of solids.

- The coupling of bubble dynamics with crystal (spinel) formation dynamics will result in a more realistic picture of the melter and will help increase melter performance, especially the melt rate.

- The formulation of optimized glasses based on actual HLW compositions should be used to validate the optimization models.

- Melter experiments should be designed to study spinel settling, and the results should be compared with a mathematical model and used for its validation. 


\section{Literature Cited}

1. D. S. Kim and J. D. Vienna, "Influence of Glass property Restrictions on Hanford HLW Glass Volume," Ceram. Trans. (in print).

2. P. Hrma and J. Alton. 2001. "Dissolution and Growth of Spinel Crystals in a High-Level Waste Glass," The $8^{\text {th }}$ International Conference Proceedings (ICEM'01), Bruges, Belgium.

3. T. J. Plaisted, J. Alton, B. K. Wilson, and P. Hrma. 2001. "Effect of Minor Component Addition on Spinel Crystallization in Simulated High-Level Waste Glass," Ceram. Trans. 119, 317-325.

4. B. K. Wilson, T. J. Plaisted, J. Alton, and P. Hrma, "The Effect of Composition on Spinel Equilibrium and Crystal Size in High-Level Waste Glass," (in review).

5. P. Hrma, P. Izak, J. D. Vienna, G. M. Irwin and M-L. Thomas, "Partial Molar Liquidus Temperatures of Multivalent Elements in Multicomponent Borosilicate Glass," Phys. Chem. Glasses (in review).

6. T. J. Plaisted, F. Mo, B. K. Wilson, C. Young, and P. Hrma. 2001. "Surface Crystallization and Composition of Spinel and Acmite in High-Level Waste Glass," Ceram. Trans. 119, 317-325.

7. J. Alton, T. J. Plaisted, and P. Hrma, "Spinel Nucleation and Growth of Spinel Crystals in a Borosilicate Glass" (in review).

8. J. G. Reynolds and P. Hrma. 1997. "The Kinetics of Spinel Crystallization from a High-Level Waste Glass," Mat. Res. Soc. Symp. Proc. 465, 261-268.

9. P. Izak, P. Hrma, B. W. Arey, and T. J. Plaisted. 2001. "Effect of Batch Melting, Temperature History, and Minor Component Addition on Spinel Crystallization in High-Level Waste Glass," J. Non-Cryst. Solids 289, 17-29.

10. P. Hrma, J. Alton, J. Klouzek, J. Matyas, M. Mika, L. Nemec, T. J. Plaisted, P. Schill, and M. Trochta. 2001. "Increasing High-Level Waste Loading in Glass without Changing the Baseline Melter Technology," Waste Management '01, University of Arizona, Tucson, Arizona.

11. P. Hrma, "Crystallization in High-Level Waste Glasses," Ceram. Trans. (in press).

12. J. Klouzek, J. Alton, T. J. Plaisted, and P. Hrma. 2001. "Crucible Study of Spinel Settling in HighLevel Waste Glass," Ceram. Trans. 119, 301-308.

13. E. Barnea, and J. Mizrahi. 1973. "A Generalized Approach to the Fluid Dynamics of Particulate Systems, Part 1," Chem. Eng. J. 5, 171-189.

14. M. Jiricka and P. Hrma. "Chemical and Mechanical Properties of Spinel Sludge in High-Level Waste Glass," Ceramic-Silikaty (in press).

15. J. Alton, T. J. Plaisted, and P. Hrma. "Modeling the Growth and Dissolution of Spinel Crystals in a Borosilicate Glass Using the KJMA and First Order Equations" (in review).

16. P. Schill, M. Trochta, J. Matyas, L. Nemec, and P. Hrma. 2001. "Mathematical Model of Spinel Settling in a Real Waste Glass Melter," Waste Management '01, University of Arizona, Tucson, Arizona.

17. J. Matyáš, J. Kloužek, L. Němec, and M. Trochta. 2001. "Spinel settling in HLW melters," The $8^{\text {th }}$ International Conference Proceedings (ICEM’01), Bruges, Belgium. 
18. J. Matyáš. 2001. Description of the Behavior of Multitude Particles in Non-isothermal Convective Melting Space, PhD. Thesis, Laboratory of Inorganic Materials, Prague, Czech Republic.

\section{Feedback}

EMSP is an excellent program that allows researchers to focus on conducting the work and communicating the results without being overburdened by administrative issues. 


\section{Appendices}

\section{Appendix A: Modeling of Spinel Settling in Waste Glass Melter}

Proposal Submitted to EMSP in March 2001

Abstract

This proposed extension of prior work will examine an interrelated set of behaviors we must know to improve waste vitrification. The results of this study will enable judging the efficiency of melters considered for high-level waste (HLW) vitrification, optimize the design and operation of melters, and optimize the formulation of HLW glasses with the maximum waste loading compatible with low-risk melter processing. The technical focus of this multi-institutional bi-national research is the formation and settling of spinel, the most common crystalline phase that precipitates in molten HLW glass. For the majority of HLW streams, spinel formation in the HLW melter limits the waste fraction in glass because accumulation of spinel may interfere with melter operation, thus shortening its lifetime. Understanding spinel formation and behavior is important for the economy of HLW vitrification because it calls for the highest waste loading that is compatible with the quality and processability of the waste form.

The first 3 years of this project resulted in publishing nearly 30 scientific papers in peer-reviewed journals and conference proceedings. This work has established the experimental and computational methodology for the fundamental understanding and modeling of the kinetics of spinel formation and the dynamics of spinel behavior in a waste-glass melter, thus fulfilling the goal of this research phase.

However, activity is needed to complete the following areas: 1) effect of glass composition on spinel behavior, 2) effect of the redox state of the melt, 3) interaction of spinel with noble metals, 4) effects of melter-design parameters, 5) effect of melter operating temperature and other conditions, 6) effect of melter idling, and 7) coupling of bubble dynamics (nucleation, growth, and motion) with spinel dynamics. The formulation of optimized glasses based on actual HLW compositions will be used to validate the optimization models. In cooperation with the Tanks Focus Area (TFA) program, we will conduct a smallscale melter experiment designed to study spinel settling and compare the results with a mathematical model.

This project combines the unique capabilities of the Pacific Northwest National Laboratory (PNNL), the Academy of Sciences of the Czech Republic (ASCR), the Institute of Chemical Technology (ICT), Prague, Czech Republic, and Glass Service (GS), Inc., Vsetin, Czech Republic, allowing this voluminous and demanding scope to be accomplished in 3 years of research. During the past 3 years, this international team has developed novel approaches and methodologies needed for each step of this complex research that combines materials science with chemical engineering and mathematical modeling.

The outcome of this study will be a more realistic model that will quantify the efficiency of melters considered for HLW vitrification, optimize the design and operation of melters, and optimize the formulation of HLW glasses with maximum waste loading compatible with low-risk melter processing. The unique experimental techniques available at PNNL, ASCR, and ICT will be used to measure crystal and bubble nucleation, growth, and dissolution under the following conditions: 1) multiple particles are suspended within the melt, 2) particles move by buoyancy and natural convention, 3) solid and gaseous particles interact, and 4) temperature changes with time (as glass experiences it) or in space (as viewed by 
the external observer). Considering that glass composition and oxygen partial pressure are variables, this study describes extremely complex interactive behavior. This complexity, which is unavoidable for the fundamental understanding of glass processing, has been the main obstacle to the rational, rather than purely empirical, approach to HLW vitrification. This complexity is also a major scientific challenge that can be met as a system of mutually coupled partial differential equations. Such a system has been used in the advanced mathematical model developed over the past 3 decades and continuously being improved at GS and ASCR. 


\section{Appendix B: Brief Summaries of Theses}

Summaries of the theses listed in Table 5 are shown below. The first two items are abstracts of M.S. theses conducted at the Institute of Chemical Technology, Prague. The third item is an extended summary of that portion of a Ph.D. thesis that was dealing with a HLW glass melter. The other part of the thesis was modeling the behavior of gas bubbles in a large furnace for the processing of commercial glass. These results are irrelevant for our topic and therefore are not summarized here.

Title: $\quad$ The Effect of Composition on Spinel Equilibrium Concentration in HLW Glass Author: $\quad$ M. Patek Supervisor: $\quad$ M. Mika

Modifying the MS-7 glass composition, we prepared six glasses with a different content of $\mathrm{Li}^{+}$(SE3), $\mathrm{Na}^{+}(\mathrm{SE}-4), \mathrm{Mg}^{2+}(\mathrm{SE}-5), \mathrm{Ni}^{2+}(\mathrm{SE}-2), \mathrm{Cr}^{3+}$ (SE-1 and SE-6), and $\mathrm{Si}^{\mathrm{IV}}$. At first, we measured the liquidus temperature $\left(T_{\mathrm{L}}\right)$ of the prepared glasses by uniform-temperature heat treatments. To determine the temperature and composition dependence of equilibrium concentration $\left(C_{0}\right)$, the samples were heat treated at roughly $T=50,75,100,125,150,175$, and $200^{\circ} \mathrm{C}$ below $T_{\mathrm{L}}$ and quenched. The spinel concentration in the glass was determined by quantitative X-ray powder diffraction (XRD) analysis using the $\mathrm{Co}-\mathrm{K}_{\alpha}$ radiation. Standards were prepared by mixing a glass powder with spinel crystals isolated from spinel sludge by acid digestion. The size of the crystals in the glasses was determined using optical microscopy.

The temperature dependence of $C_{0}$ is strongly influenced by the solubility of $\mathrm{Ni}^{2+}$, a spinel component that can act as a nucleation agent. Its solubility is probably affected by $\mathrm{Mg}^{2+}$ occupying sites suitable for $\mathrm{Ni}^{2+}$. Another spinel component, $\mathrm{Cr}^{3+}$, also acts as a nucleating agent, but shifts the $C_{0}$ versus $T$ dependence to higher temperatures where the solubility of other spinel components is higher; hence, the dependence is less steep. The significant difference in the slopes of SE-2 and SE-6 glasses might indicate that Ni-rich spinel (e.g., $\mathrm{NiFe}_{2} \mathrm{O}_{4}$ ) forms more readily than Cr-rich spinel (e.g., $\mathrm{FeCr}_{2} \mathrm{O}_{4}$ ). The $C_{0}$ is sensitive to the supersaturation of the $\mathrm{Ni}^{2+}$ in the melt that plays major role in spinel formation. Reducing $\mathrm{Li}^{+}$or $\mathrm{Na}^{+}$slightly decreased $\mathrm{d} C_{0} / \mathrm{d} T$. These atoms are replaced by $\mathrm{Si}^{\mathrm{IV}}$, which increases the atom\% of $\mathrm{O}$ and the number of bridging oxygens. Hence spinel components are more diluted and the lower supersaturation results in the smaller slope.

The crystal size depends on the nucleation rate that is significantly influenced by the nucleating agents. Therefore, the smallest crystals $(\sim 2 \mu \mathrm{m})$ were found in the glasses with the increased content of $\mathrm{Ni}^{2+}$ or $\mathrm{Cr}^{3+}$, which also had the highest $n_{s}$, about $10^{6}$ per $\mathrm{mm}^{3}$. The rate of spinel settling decreases as the size of the crystals decreases; hence, the crystals accumulate more slowly in the melter.

From our study, it follows that $\mathrm{Cr}^{3+}$ strongly increases $T_{\mathrm{L}}$, but has only a small effect on the temperature dependence of $C_{0}$; this is favorable to the processing of high-Cr wastes. Problems can be caused by a higher content of $\mathrm{Mg}^{2+}$ in HLW glass because $\mathrm{Mg}^{2+}$ significantly decreases spinel solubility without decreasing the size of spinel crystals. 
Title: $\quad$ Spinel Crystallization in Borosilicate Glasses for Radioactive Waste Disposal

Author: $\quad$ O. Stahlavsky

Supervisor: M. Mika

We studied the effect of temperature history and a nucleation agent on nucleation, growth, and dissolution of spinel crystals. We used the MS-7 glass and MS-7N glass that contained 0.1 mass\% of $\mathrm{Rh}_{2} \mathrm{O}_{3}$. Spinel crystals were developed by heat treatment of 5-g glass samples in covered Pt crucibles. At first the glass MS-7 was treated at $1200^{\circ} \mathrm{C}$ for $30 \mathrm{~min}$ to destroy any possible nuclei, then cooled down to $1000^{\circ} \mathrm{C}$ where the melt dwelled for $30,60,90,120,150$, and $180 \mathrm{~min}$. The heat treated samples were studied by optical microscopy, image analysis, and X-ray quantitative analysis. Planar information obtained from optical microscopy was transformed to volume data assuming the octahedral shape of spinel crystals.

We found that spinel crystals nucleated after an incubation time of about $11 \mathrm{~min}$. Then their number density $\left(n_{\mathrm{s}}\right)$ increased almost linearly with time reaching a maximum at $90 \mathrm{~min}$. From that point we observed a slow decrease of $n_{\mathrm{s}}$ along with the increase of spinel mass concentration and crystal size. This phenomenon is similar to the Oswald ripening of crystals (the system tends to decrease its interfacial energy by dissolving small crystals and feeding larger crystals). The estimated nucleation rate was approximately $0.08 \mathrm{~s}^{-1}$, corresponding to about $10^{-12} \mathrm{~m}^{2} \cdot \mathrm{s}^{-1}$ diffusion coefficient of spinel forming components in glass at $1000^{\circ} \mathrm{C}$.

Using size classes for spinel crystals, we determined the change of crystal size distribution with time for different heat-treatment histories. Repeated undercooling of a melt already containing crystals reveled that the system preferred growing of existing crystals to nucleating new crystals.

Experiments with the dissolution of spinel crystals showed that crystals with the edge length shorter than $10 \mu \mathrm{m}$ dissolved extremely fast. The addition of $\mathrm{Rh}_{2} \mathrm{O}_{3}$, acting as a nucleation agent, suppressed the incubation time and increased the $n_{\mathrm{s}}$ by $10^{4}$. 
Title:

Mathematical Model of the Distribution and Settling of Spinel Crystals in a High-Level Waste Melter

Author: J. Matyas

Supervisor: L. Nemec

\section{Theory}

The settling of spinel crystals on the bottom and in the channel of a high-level waste (HLW) glass melter interferes with melter operation and shortens melter lifetime. A mathematical model was developed to calculate the rate of the deposition of spinel in the melter and to estimate the influence of spinel on the performance of a real waste-glass melter over its lifetime.

Two minor effects were omitted for simplicity: the impact of spinel suspended in the melt and the impact of the growing sludge layer on the macroscopic melt flow. The distributions of glass velocities and temperatures in the melter were calculated using a 3-D mathematical model of glass flow and heat transfer in the melter space coupled through temperature-dependent properties of the glass. The procedure of control volumes was used [1]. This mathematical model involved the kinetics of growth and dissolution of spinel crystals, the class representation of spinel crystal size distribution, and the algorithms for the moving and settling of spinel crystals inside of the melter.

The crystals form, grow, or dissolve in accordance with internal melter conditions. The HixonCrowell equation was used for the kinetic description of crystal growth and dissolution [2]:

$$
\frac{d a}{d t}=k_{H}\left(C_{\text {melt }}-C_{\text {surf }}\right)
$$

Here $a$ is the spinel crystal size, $k_{H}$ is the mass-transfer coefficient, $C_{\text {surf }}$ is the volume fraction of dissolved spinel at the crystal surface, and $C_{\text {melt }}$ is volume fraction of spinel dissolved in the melt. At equilibrium $C_{\text {melt }}=C_{\text {surf }}$; thus,

$$
\begin{aligned}
& C_{\text {melt }}=C_{\text {max }}-C \\
& C_{\text {surf }}=C_{\text {max }}-C_{0},
\end{aligned}
$$

where $C_{0}$ is the equilibrium volume fraction of spinel crystals in glass, $C_{\max }$ is the volume fraction of oxides that form spinel crystals, and $C$ is the volume fraction of spinel crystals in molten glass. Hence, Equation (1) becomes:

$$
\frac{d a}{d t}=k_{H}\left(C_{0}-C\right)
$$

Equation (3) was used in the mathematical model.

Several parameters in Equation (3) are temperature dependent. The mass-transfer coefficient is expressed by an Arrhenius function [3]: 


$$
k_{H}=k_{0} \exp \left(-\frac{B_{K}}{T}\right)
$$

where $B_{k}$ and $k_{0}$ are temperature independent coefficients that were obtained from experimental data.

The equilibrium fraction of spinel crystals, $C_{0}$, depends on temperature according to the Le Chatelier equation:

$$
C_{0}=C_{\max }\left\{1-\exp \left[-B_{L}\left(\frac{1}{T}-\frac{1}{T_{L}}\right)\right]\right\},
$$

where $T_{L}$ is the liquidus temperature and $C_{\max }$ and $B_{L}$ are composition-dependent coefficients [3].

To represent the distribution of crystal sizes in each control volume, $n$ classes of crystal sizes were used in calculations $(n=20)$, described by their center (the mean size of the $i$-th size class, $\left.a_{i}\right)$ and by their equivalent width $\left(w_{i}\right)$; thus,

$$
\sum_{i=1}^{n} w_{i}=a_{\max }
$$

The volume fraction of crystals in the control volume was calculated as

$$
C=\sum_{i=1}^{n} N_{v_{i}} a_{i}^{3}
$$

The crystals' distribution was calculated considering the polydisperzed spinel transport by melt convection and the settling of crystals according to the Stokes' law. The mass balance of the crystalline phase was used for each size class in the form:

$$
\frac{\partial}{\partial t}\left(\rho N_{V_{i}}\right)+\frac{\partial}{\partial x}\left(\rho u N_{V_{i}}\right)+\frac{\partial}{\partial y}\left(\rho v N_{V_{i}}\right)+\frac{\partial}{\partial z}\left(\rho\left(w+w_{s}\right) N_{V_{i}}\right)=0,
$$

where $w_{s}$ is the Stokes velocity of spinel crystals in glass,

$$
w_{s}=\frac{0.205 g\left(\rho_{s}-\rho_{g l}\right) a_{i}^{2}}{\mu}
$$

Here $g$ is the gravity acceleration, $\eta$ is the dynamic viscosity of the melt, and $\rho_{s}$ and $\rho_{g l}$ are the densities of spinel crystals and glass.

The thickness of the sludge layer on the melter bottom and the slant melter walls was calculated from the mass balance of spinel crystals in the regions adjacent to the bottom and from the measured concentration of spinel in the sludge. In each control volume above the bottom, the $i$-th size height, $h_{i}$, was calculated for the time step $\Delta t$ as 


$$
h_{i}=\Delta t w_{s i} .
$$

All crystals within $h_{i}$ fall fast enough to settle on the bottom during $\Delta t$. The settled fraction of crystals in the control volume is then

$$
s_{i}=\frac{h_{i}}{\Delta z},
$$

where $\Delta z$ is the height of the control volume. The height of the sludge layer is:

$$
h=\frac{\Delta z \sum_{i=1}^{n} s_{i} N_{V_{i}} a_{i}^{3}}{V_{s}},
$$

where the $V_{s}$ is the volume fraction of spinel crystals in the sludge.

Spinel crystals enter the melt from the cold cap, the layer of the melting batch that floats on the glass level. Their input concentration and size were measured using crucible experiments. In these experiments, dry feed was heat-treated according to the time temperature regime inside the cold cap estimated from the mathematical model. The input crystals concentration, $C_{i n}=110.1 \mathrm{~kg} / \mathrm{m}^{3}$, was determined using X-ray diffraction. The monodisperse crystal size, $a_{i n}=1 \mu \mathrm{m}$, was obtained using LUCIA image analysis.

The measured nucleation density of spinel was

$$
n_{s}(T)=10^{9} \exp ((-0.010823 T)+13.622)
$$

The number of spinel crystals moving from one control volume to another in the region where $\mathrm{T}<T_{L}$ was increased to match $n_{s}(T)$ if the next control volume was cooler than $T_{L}$, and the current number of particles was lower than $n_{s}(T)$. New nuclei were generated in the size class of the smallest crystals.

\section{$\underline{\text { Model Calculations }}$}

For each time step, the mathematical model performs the following sequence of operations:

1. The temperature and velocity fields are loaded from the GS Glass Furnace Model.

2. The nucleation of spinel crystals is introduced.

3. Equation (9) is solved for each size class of crystals (each size class of crystal is treated separately).

4. Changes in spinel concentrations and crystal numbers by crystal growth or dissolution are calculated for each size class of crystal:

$$
\frac{d a_{i}}{d t}=k(T)\left[C_{0}-\sum_{i=1}^{n} N_{v_{i}} a_{i}^{3}\right]
$$

5. Crystals are redistributed into unified size classes.

6. The calculation of crystal settling in control volumes above the bottom and above the slant walls completes the calculation cycle.

Steps 2 through 6 are repeated to reach the stationary state. 
The values of property coefficients, listed in Table I, were obtained from experiments and used in the mathematical simulation of spinel settling [4-6]:

Table I. Property Coefficients

\begin{tabular}{|l||}
\hline$a^{*}=0.225 \mu \mathrm{m}$ \\
\hline$B_{K}=24891 \mathrm{~K}$ \\
\hline$k_{0}=0.1777 \mathrm{~m} / \mathrm{s}$ \\
\hline$T_{L}=1078^{\circ} \mathrm{C}$ \\
\hline$C_{\max }=0.04334 \mathrm{~m}^{3} / \mathrm{m}^{3}$ \\
\hline$B_{L}=5110.7 \mathrm{~K}$ \\
\hline$\rho_{s}=5140 \mathrm{~kg} / \mathrm{m}^{3}$ \\
\hline$V_{S}=0.16$ \\
\hline$a^{*}$ is the size of nucleated spinel crystals
\end{tabular}

\section{$\underline{\text { Results and Discussion }}$}

Figure 1 displays the stationary temperature and velocity fields in the cross section through the melting space calculated by the GS Glass Furnace Model. The figure shows a nearly uniform temperature field and two vortices of the natural convective flow of the melt driven by electric heating. The maximum temperature did not exceed $1200^{\circ} \mathrm{C}$. The average temperature of the molten glass was $1142.7^{\circ} \mathrm{C}$. The average glass velocity was approximately one order of magnitude higher compared to standard industrial glass furnaces.

Infilling of the melting space by spinel crystals from zero initial concentration is shown in Figure 2. The distribution of spinel crystals in the longitudinal and cross section for the calculated reference case $\left(a_{i n}=1 \mu \mathrm{m}, C_{i n}=110.1 \mathrm{~kg} / \mathrm{m}^{3}\right)$ is displayed in Figure 3. The intensive mixing of the glass melt results in an almost exponential increase of spinel crystal concentration in Figure 2 and a relatively uniform distribution of crystals in the melting space in Figure 3. Hence, the HLW melter under study behaves as a nearly ideal mixer.

The sludge layer thickness profile at the melter bottom for the reference case after one year of melter performance is shown in Figure 4. Note the increased layer thickness towards the melter outflow. The sludge layer is thin. The reference-case sludge would not interfere with melter operation.

Figures 5 to 8 present results of the parametric study conducted to investigate the influence of the input crystal size, the input crystal concentration, the average temperature in the melting space, and the liquidus temperature on the sludge-layer growth. 


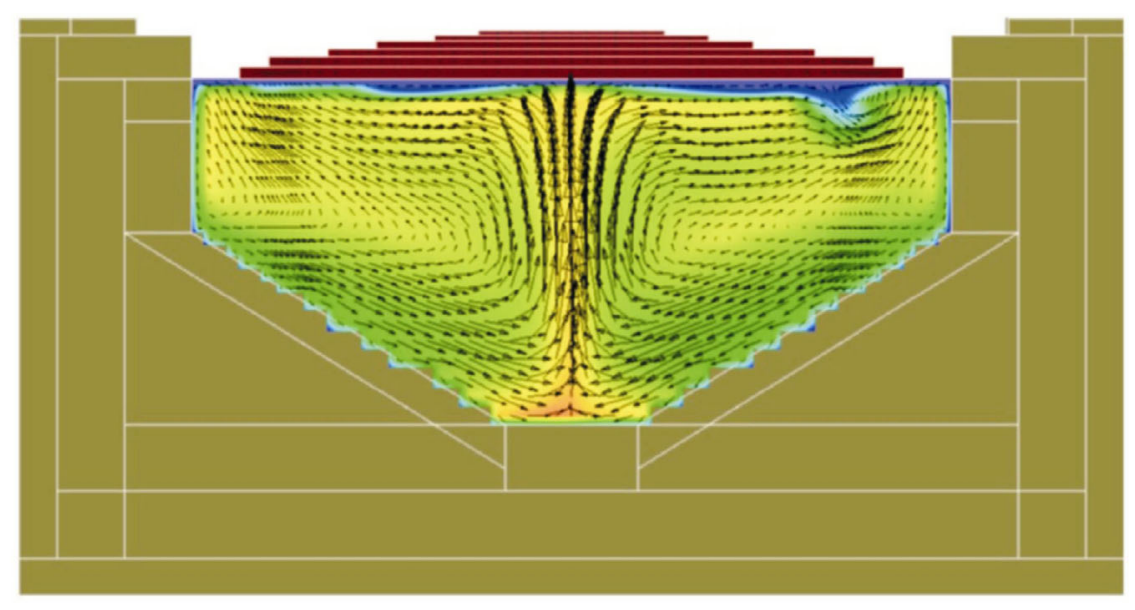

\section{temperature $\left[{ }^{\circ} \mathrm{C}\right]$}

Figure 1. Stationary Temperature and Velocity Fields in the Cross Section of the HLW Melter

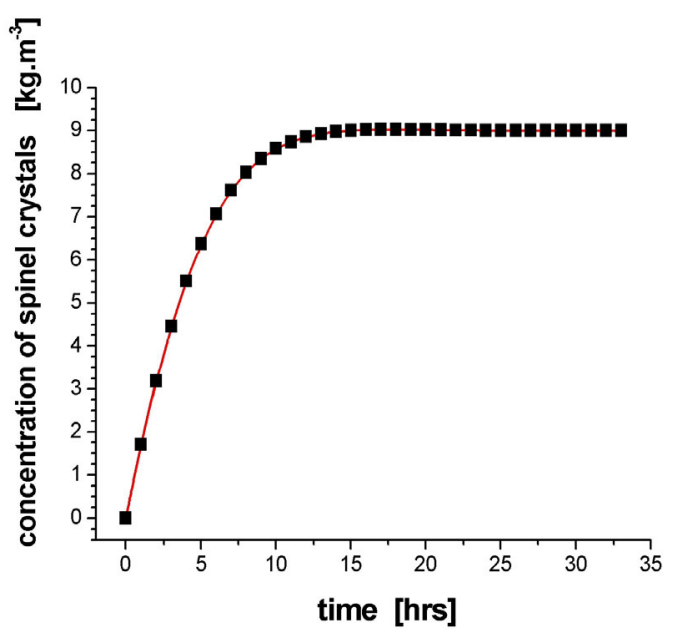

Figure 2. The Time Development of Spinel Crystal Concentration During HLW Melter Feeding (reference case).

The parabolic dependence on the input size of spinel crystals is seen in Figure 5. Crystals larger than $10 \mu \mathrm{m}$ would produce a sludge layer several $\mathrm{cm}$ thick after one year of melter performance. The melter outflow would be gradually obstructed with continuous operation.

As Figures 6, 7, and 8 show, the sludge-layer thickness mildly grows with increasing input concentration of spinel crystals, increasing average melt temperature, and increasing $T_{L}$. Within broad ranges of variation, these parameters should not cause technological problems by their impact on spinel settling. The layer of deposited crystals will remain thinner than $100 \mu \mathrm{m}$ per year. The most important parameter for the sludge-layer growth control is the size of spinel crystals. 


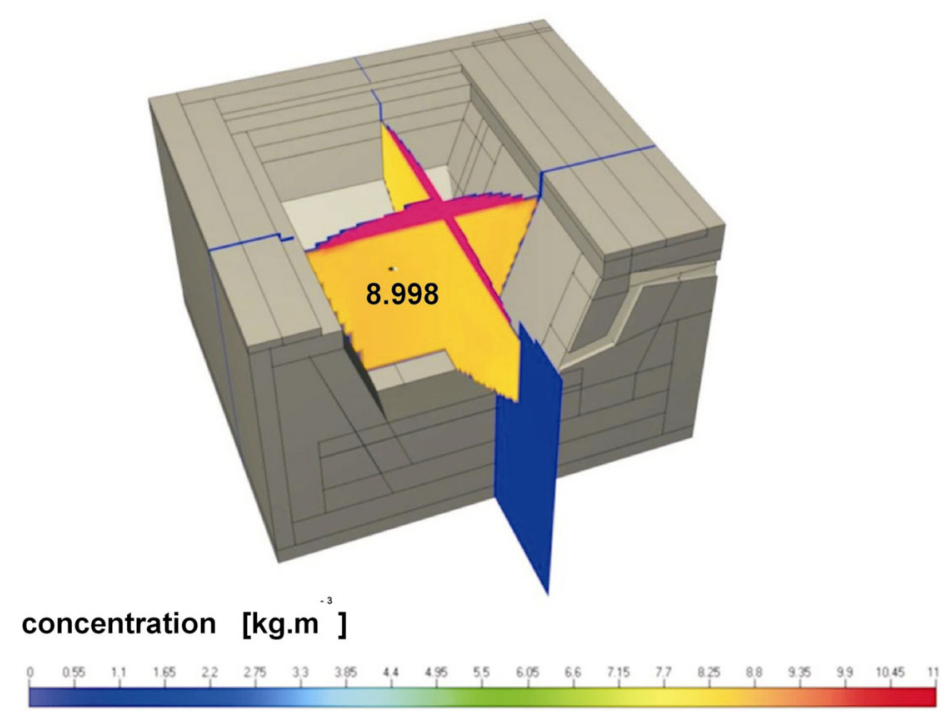

Figure 3. Calculated Stationary Concentration of Spinel Crystals in the Longitudinal and Cross Section (reference case)

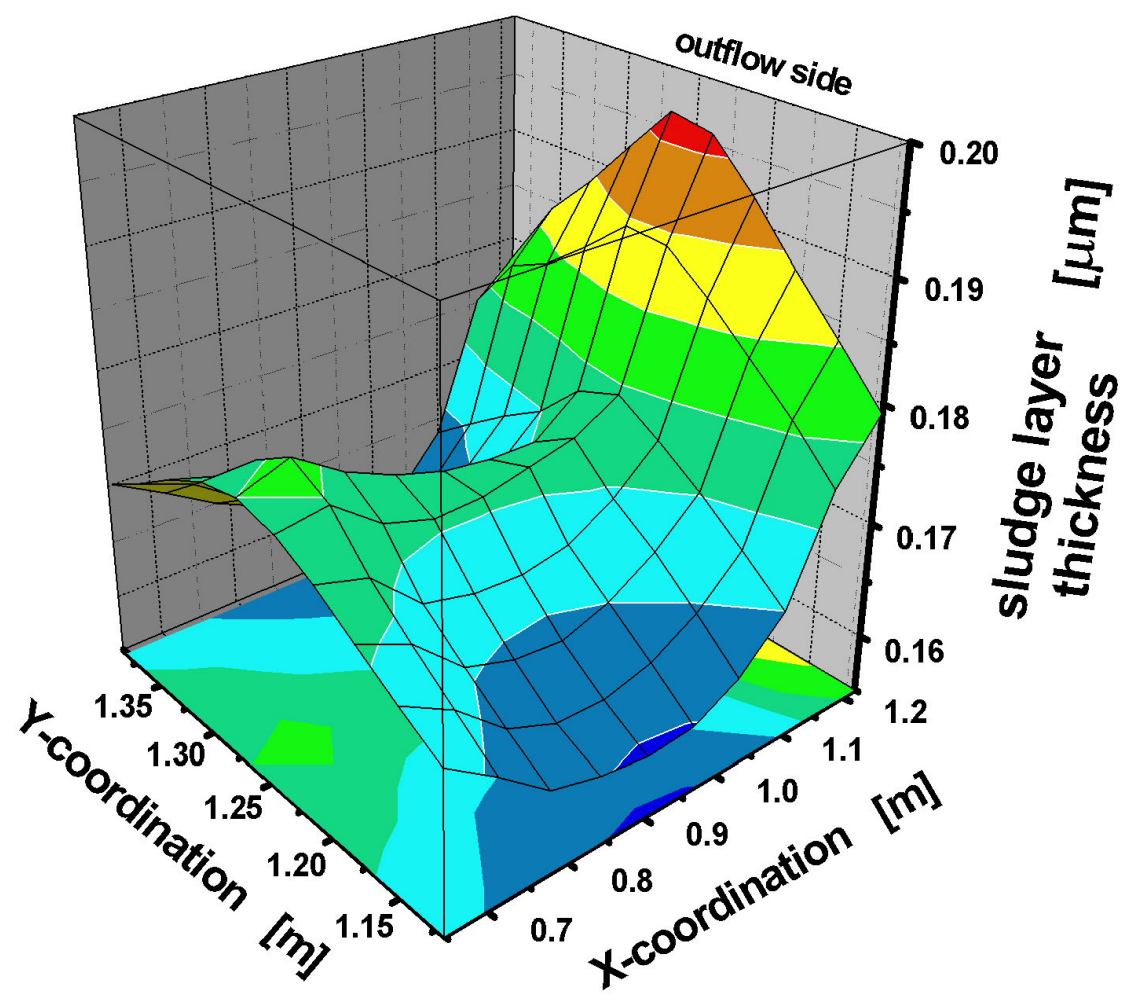

Figure 4. The Thickness Profile of Deposited Spinel Crystals (the sludge layer) at the Bottom After $30 \mathrm{~h}$ of HLW Melter Performance (reference case) 


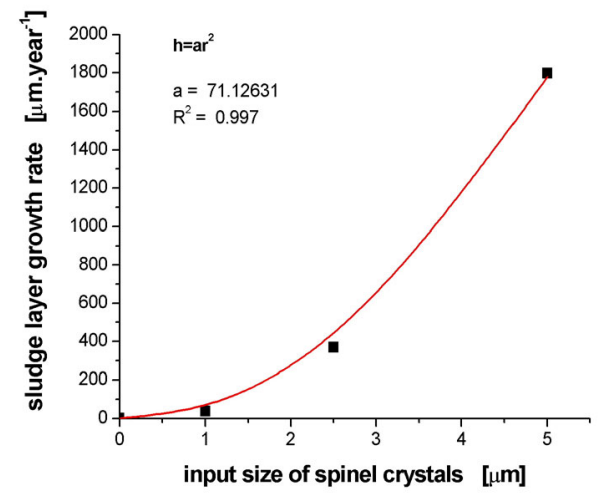

Figure 5. The Effect of the Size of Input Crystals on the Thickness of the Sludge Layer of Deposited Spinel Crystals at the HLW Melter Bottom After One Year of Melter Performance

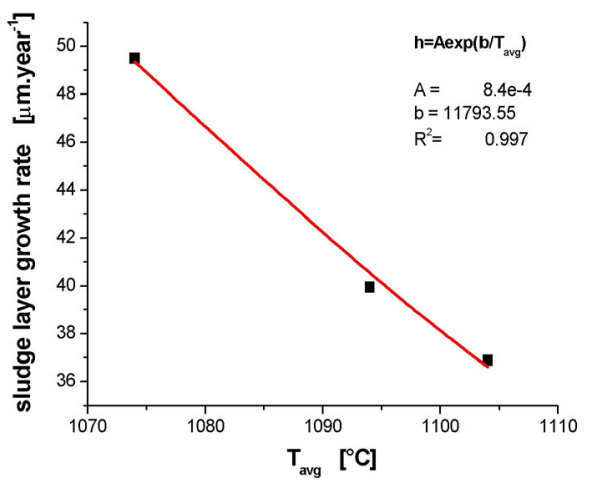

Figure 7. The Effect of the Average Glass Temperature on the Thickness of the Sludge Layer of Deposited Spinel Crystals at the HLW Melter Bottom After One Year of Melter Performance

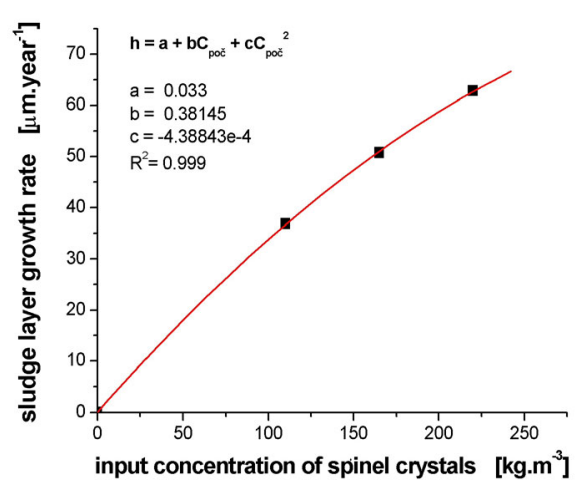

Figure 6. The Effect of Input Crystal Concentration on the Thickness of the Sludge Layer of Deposited Spinel Crystals at the HLW Melter Bottom After One Year of Melter Performance

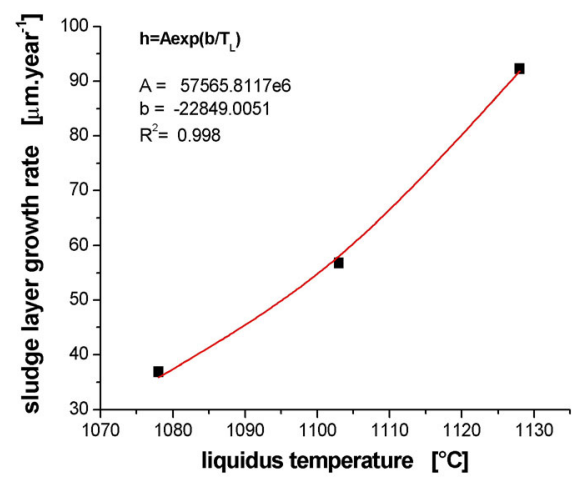

Figure 8. The Effect of the Liquidus Temperature on the Thickness of the Sludge Layer of Deposited Spinel Crystals at the HLW Melter Bottom After One Year of Melter Performance

\section{Conclusion}

The mathematical model presented enables calculating the distribution of spinel crystal concentration within the melt and the evolution of the spinel layer thickness on the HLW glass melter bottom. The model is a powerful tool for melter operation control. It predicts the sludge-layer thickness and possible blockage of outflow from the melter.

\section{Literature Cited}

1. Schill P. Proceedings of the International Congress on Glass, Vol 29, 336-343, Leningrad (1989).

2. Hixon A.W, and Crowell J.H. "Dependence of Reaction Velocity upon Surface and Agitation," Industrial and Engineering Chemistry 23 (8), 923-931 (1931). 
3. Plaisted T.J., Mo F., Young J.S., and Hrma P. "Surface Crystallization and Composition of Spinel and Acmite in High-Level Waste Glass", Ceram. Trans. 119, 317-325 (2001).

4. Hrma P., Vienna J.D., Crum J.V., Piepel G.F., Míka M. "Liquidus Temperature of High-Level Waste Borosilicate Glasses with Spinel Primary Phase," Mat. Res. Soc. Proc. 608, 671-676 (2000).

5. Wilson B.K., Plaisted T.J, Alton J., Hrma P. "The Effect of Composition on Spinel Equilibrium and Crystal Size in High-Level Waste Glass," in review.

6. Míka M., Hrma P., Schweiger M.J. "Rheology of Spinel Sludge in Molten Glass", Ceramics 44, 3, 86-90 (2000). 


\section{Appendix C: Crystal Distribution and Settling in a HLW Glass Melter - Ideal Mixer Model}

This Appendix provides a rough draft of a recent work resulting from the development of a hybrid model for a fast-mixing HLW glass melter (the West Valley type). The model is based partly on the outcome of a complete mathematical model of the melter and partly on the mass balance of the crystalline phase in the melter operating as an ideal mixer.

\section{Theoretical}

The results obtained by mathematical modeling of an electrically heated HLW melter have shown that an intensive mixing of glass sets in the melter as a consequence of thermal convection. Consequently, an almost homogeneous distribution of inputting and nucleated crystals (e.g., spinel crystals) was obvious after the melter reached the stationary state [1]. The response characteristics of the melter, obtained from the concentration increase of spinel crystals in the melter during the initial period, confirmed an almost ideal mixing and zero dead volume in the melter. Relatively small temperature differences were observed inside of the melter, supporting the idea of an ideal mixer.

The mentioned results lead to the idea to treat the HLW as an ideally mixed, isothermal pot. In this case, the concentration of spinel crystals inside the melter is nearly uniform and the stationary concentration of spinel crystals in the melter can be obtained from the mass balance of crystals.

When balancing the crystals in the melter, two monodisperse sources of crystals (a balance including entering polydisperse crystals may also be considered) are taken into account: crystals coming from the batch (cold cap) and entering the melter through the top level, and nucleated crystals. The crystal sources are active simultaneously only when the melt temperature is lower than glass liquidus temperature, $T<$ $T_{L}$, and $C_{i n}<C_{o}$, where $C_{i n}$ is the concentration of crystals entering from the batch and $C_{o}$ is the equilibrium concentration of crystals in the melt. Under mentioned conditions, all crystals present in the melter will grow. The total change of crystal concentration in the melter by crystal input is expressed as

$$
d C(\text { in })=\frac{\dot{V}\left(C_{i n}+C_{N o}\right)}{V} d \tau
$$

where $C_{N o}$ is the input concentration of nucleated crystals, $V$ is the melter volume and $\dot{V}$ its melt throughput.

For $C_{N o}$ we have

$$
C_{N o}=N_{N o} a_{c r i t}^{3} \rho_{s}
$$

where $N_{N o}$ is number density of nucleated crystals, $a_{c r i t}$ is the critical size of nucleated crystals, and $\rho_{s}$ is the spinel crystal density.

The mass flow of crystals entering the melt through the cold cap is

$$
\dot{m}_{C C o}=C_{i n} \dot{V}
$$


Similarly, the mass flow of nucleated crystals, which are formed instantly after the glass has entered the melter, is

$$
\dot{m}_{N o}=N_{N o} \dot{V} a_{c r i t}^{3} \rho_{s}
$$

The number of crystals entering the melter from the cold cap per time unit is

$$
\dot{N}_{C C o}=\frac{\dot{m}_{C C o}}{a_{o}^{3} \rho_{s}}=\frac{C_{i n} \dot{V}}{a_{o}^{3} \rho_{s}}
$$

Similarly, the flow of nucleated crystals is

$$
\dot{N}_{N o}=\frac{\dot{m}_{N o}}{a_{c r i t}^{3} \rho_{s}}=N_{N o} \dot{\mathrm{V}}
$$

As all crystals in the melter grow (no crystals are lost by dissolution because $T<T_{L}$ ) and the amount of settled crystals is small, the initial ratio between the numbers of crystals from the cold cap and nucleated crystals is constant:

$$
\frac{\dot{N}_{C C o}}{\dot{N}_{N o}}=\frac{N_{C C}}{N_{N}}=\frac{C_{i n}}{a_{o}^{3} \rho_{s} N_{N o}}
$$

where $N_{C C}$ and $N_{N}$ are the number densities of crystals from the cold cap and nucleated crystals, respectively.

The concentration of crystals in the melter, coming from the cold cap is

$$
C_{C C}=N_{C C} \bar{a}_{C C}^{3} \rho_{s}
$$

where $\bar{a}_{C C}$ is the average size of crystals from the cold cap. Similarly,

$$
C_{N}=N_{N} \bar{a}_{N}^{3} \rho_{s}
$$

where $\bar{a}_{N}$ is the average size of nucleated crystals.

The constant ratio between both concentrations is obtained by combining Equations (8), (9), and (7):

$$
\frac{C_{C C}}{C_{N}}=\frac{C_{i n}}{a_{o}^{3} \rho_{s}} \quad \frac{1}{N_{N o}} \quad \frac{\bar{a}_{C C}^{3}}{\bar{a}_{N}^{3}}=\frac{C_{\text {in }}}{a_{o}^{3} \rho_{s} N_{N o}} \quad \frac{\left(a_{o}+\dot{a} \bar{\tau}\right)^{3}}{\left(a_{c r i t}+\dot{a} \bar{\tau}\right)^{3}}
$$

where $\bar{a}=a_{o}+\dot{a} \bar{\tau}, \dot{a}$ is the average crystal growth rate and $\bar{\tau}$ is the average residence time of glass in the melter.

As all crystals present in the melter are coming from the cold cap or are nucleated in the melter, 


$$
C=C_{C C}+C_{N}
$$

where $C$ is the total crystal concentration in the melter.

Both crystal concentrations may be expressed separately by using Equations (10) and (11):

$$
\begin{gathered}
C_{N}=C \frac{1}{\frac{C_{i n}}{a_{o}^{3} \rho_{s} N_{N o}} \frac{\left(a_{o}+\dot{a} \bar{\tau}\right)^{3}}{\left(a_{c r i t}+\dot{a} \bar{\tau}\right)^{3}}+1} \\
C_{C C}=C\left[1-\frac{1}{\frac{C_{i n}}{a_{o}^{3} \rho_{s} N_{N o}} \frac{\left(a_{o}+\dot{a} \bar{\tau}\right)^{3}}{\left(a_{c r i t}+\dot{a} \bar{\tau}\right)^{3}}}\right]
\end{gathered}
$$

If the expression coming from Equations (12a) and (13a) is designated as $A$, we have

$$
\begin{gathered}
C_{N}=C . A \\
C_{C C}=C(1-A)
\end{gathered}
$$

The concentration change of crystals coming from the cold cap is then

$$
d C_{C C}(\dot{a})=N_{C C} 3 \bar{a}_{C C}^{2} \dot{a} \rho_{s} d \tau
$$

and

$$
d C_{N}(\dot{a})=N_{N} 3 \bar{a}_{N}^{2} \dot{a} \rho_{s} d \tau
$$

The actual number of crystals from both sources is given by Equations (8) and (9). When applying e Equations (12b) and (13b), Equations (14) and (15) can by written as

$$
d C_{C C}(\dot{a})=(1-A) \frac{3 C \dot{a}}{\left(a_{o}+\dot{a} \bar{\tau}\right)} d \tau
$$

and

$$
d C_{N}(\dot{a})=A \frac{3 C \dot{a}}{a_{c r i t}+\dot{a} \bar{\tau}} d \tau
$$

The amount of settled crystals can be expressed as follows 


$$
\begin{gathered}
d C_{C C}(\text { settling })=-\frac{\bar{v}_{C C} S}{V} C_{C C} d \tau \\
d C_{N}(\text { setling })=-\frac{\bar{v}_{N} S}{V} C_{N} d \tau
\end{gathered}
$$

where $\bar{v}_{C C}$ and $\bar{v}_{N}$ are the settling velocities of crystals coming from the cold cap and nucleated crystals, respectively.

After applying the Stokes' law for settling velocity and Equations (12b) and (13b), we obtain

$$
d C_{C C}(\text { settling })=-\frac{0.205 g \Delta \rho}{\eta}\left(a_{o}+\dot{a} \tau\right)^{2} \frac{S}{V} C(1-A) d \tau
$$

and

$$
d C_{N}(\text { settling })=-\frac{0.205 g \Delta \rho}{\eta}\left(a_{c r i t}+\dot{a} \bar{\tau}\right)^{2} \frac{S}{V} C A d \tau
$$

where $\Delta \rho$ is the density difference of crystals and glass, $\eta$ is the glass viscosity, and $S$ is the surface of the melter where crystals settle. Finally, the concentration change brought about by glass output is

$$
d C(\text { out })=-\frac{\dot{V} C}{V} d \tau
$$

Adding Equations (1), (16), (17), (20), (21), and (22), and solving the resulting equation for $\tau \rightarrow \infty$ (stationary state), we obtain the total crystal concentration in the melter:

$$
C_{\infty}=\frac{\dot{V}\left(C_{i n}+N_{N o} a_{c r i t}^{3} \rho_{s}\right)}{\frac{0.205 g \Delta \rho}{\eta}\left[\left(a_{o}+\dot{a} \bar{\tau}\right)^{2}(1-A)+\left(a_{c r i t}+\dot{a} \bar{\tau}\right)^{2} A\right] S+\dot{V}-\frac{3(1-A) \dot{a} V}{a_{o}+\dot{a} \bar{\tau}}-\frac{3 A \dot{a} V}{a_{c r i t}+\dot{a} \bar{\tau}}}
$$

If the crystal nucleation is negligible, $N_{N o} \rightarrow 0$, then $A \rightarrow 0$, and only crystals from the cold cap are present. Thus,

$$
C_{\infty}=\frac{\dot{V} C_{i n}}{\frac{0.205 g \Delta \rho}{\eta}\left(a_{o}+\dot{a} \bar{\tau}\right)^{2} S+\dot{V}-\frac{3 \dot{a} V}{a_{o}+\dot{a} \bar{\tau}}}
$$

If, on the contrary, $C_{i n} \rightarrow 0$ and $T \prec T_{L}, \quad A \rightarrow 1$, and we get from Equation (23) 


$$
C_{\infty}=\frac{\dot{V} N_{N o} a_{c r i t}^{3} \rho_{s}}{\frac{0.205 g \Delta \rho}{\eta}\left(a_{c r i t}+\dot{a} \bar{\tau}\right)^{2} S+\dot{V}-\frac{3 \dot{a} V}{a_{c r i t}+\dot{a} \bar{\tau}}}
$$

For the thickness of the layer of settled crystals on the melter bottom, we have

$$
m_{s C C}=\bar{v}_{C C} \cdot C \infty(1-A) \tau
$$

where $m_{s C C}$ is the amount of crystal settled on the bottom surface unit.

Similarly,

$$
m_{s N}=\bar{v}_{N} \cdot C_{\infty} A \tau
$$

The total layer thickness is

$$
h_{C r}(\tau)=\frac{m_{s C C}}{C_{\text {layer }}}+\frac{m_{s N}}{C_{\text {layer }}}=\frac{\left[\bar{v}_{C C} C_{\infty}(1-A)+\bar{v}_{N} C_{\infty} A\right]}{C_{\text {layer }}} \tau
$$

where $C_{\text {layer }}$ is the mass concentration of crystals in the sludge layer.

Substituting for $\bar{v}_{C C}$ and $\bar{v}_{N}$ from Equations (20) and (21), we obtain

$$
h_{c r}(\tau)=\frac{0.205 g \Delta \rho}{\eta C_{\text {layer }}}\left\{\left(a_{o}+\dot{a} \bar{\tau}\right)^{2} C_{\infty}(1-A)+\left(a_{c r i t}+\dot{a} \bar{\tau}\right)^{2} C_{\infty} A\right\} \tau
$$

where $C_{\infty}$ comes from Equation (23).

Similarly, as for $C_{\infty}, h_{C r}$ expresses the thickness of a layer consisting of crystals coming from the cold cap if $A \rightarrow 0$ and nucleated crystals if $A \rightarrow 1$.

If the crystals inputting the melter from the cold cap are polydisperse, the procedure is similar to that applied for monodisperse crystals. The ratio between number densities of inputting crystals is assumed constant also in the melter.

If the melter temperature is higher than $T_{L}$, or the crystal input concentration from the cold cap is sufficiently high, $C_{i n}>C_{o}$, crystals dissolve and no crystals can be nucleated in the melter $\left(N_{N o}=0 ; A=0\right.$; see Equation (24)). In this case, the average residence time of crystals in the melter, $\bar{\tau}_{C r}$, may be lower than the average residence time of glass, provided some crystals completely dissolve. Denoting the maximum residence time of glass as $\tau_{\max }$ and the dissolution time of the average crystal is $\tau_{\text {diss }}=-\frac{a_{o}}{\dot{a}}$, then $\bar{\tau}_{\mathrm{cr}}=\bar{\tau}$ if simultaneously $\tau_{\text {diss }} \succ \tau_{\max }$ (no crystals dissolve). If $\tau_{\text {diss }} \prec \tau_{\max }$, some crystals completely dissolve and $\bar{\tau}_{c r} \prec \bar{\tau}$. The $\bar{\tau}_{c r}$ can be calculated from the equation. 


$$
\bar{\tau}_{c r}=\int_{0}^{\tau_{d i s s}} f(\tau) \tau d \tau+\int_{\tau_{d i s s}}^{\tau_{\max }} f(\tau) \tau_{\text {diss }} d \tau
$$

Here, $f(\tau)$ is the probability density function for the distribution of glass residence times in the melter.

Thus, the first term on the right side of Equation (30) expresses the portion of the average residence time of undissolved crystals (crystals in glass with low residence time), the second term expresses the portion of the average residence time of dissolved crystals (glass melt residence times are $>\tau_{\text {diss }}$ ).

The value of $\bar{\tau}_{C r}$ should be therefore put into the mass balance of all crystals in Equation (24). In this case, the average crystal size, $\bar{a}=a_{0}+\dot{a} \bar{\tau}_{C r}$, involves both undissolved and dissolved crystals, i.e. its value is only fictitious (it can be used only in the mass balance of all crystals, Equation (24)).

The average residence time of actually present crystals can be derived from the first term on the right side of Equation (30). The density probability function of non-dissolved crystals is

$$
f^{\prime}(\tau)=\frac{f(\tau)}{\int_{o}^{\tau_{\text {diss }}} f(\tau) d \tau}
$$

and the average residence time of undissolved crystals is described by the equation

$$
\bar{\tau}_{c r}=\frac{\int_{0}^{\tau_{\text {diss }}} f(\tau) \tau d \tau}{\int_{0}^{\tau_{\text {diss }}} f(\tau) d \tau}
$$

The value of $\bar{\tau}_{C r}$ ' should be then used in Equation (29) instead of $\bar{\tau}$. In this case, $A=0$. The crystals having residence time in the melter longer than $\tau_{\text {diss }}$ completely dissolve; however their actual concentration in the melter is nonzero. Because we accepted the concept of the average size of crystals, $\bar{a}$, and the time all dissolved crystals spend in the melter is $\tau_{\text {diss }}$, then $\bar{a}=a_{0}-\dot{a} \frac{a_{0}}{\dot{a}}=0$.

To get the values $\bar{\tau}_{C r}$ and $\bar{\tau}_{c r}$ ' for an ideal mixer, the mass balance of crystals can also be used but no crystal nucleation, growing or dissolution, and settling can be considered. In this case, $C_{\infty}=C_{i n}$ and the filling of the mixer volume by new glass is expressed as

$$
C=C_{i n}\left[1-\exp \left(-\frac{\dot{V}}{V} \tau\right)\right]
$$


As the probability density function of glass residence times in the mixer is given by $\frac{1}{C_{i n}} \frac{d C}{d \tau}$, the $f(\tau)$ function has the form

$$
f(\tau)=\frac{1}{C_{\text {in }}} \frac{d C}{d \tau}=\frac{\dot{V}}{V} \exp \left(-\frac{\dot{V}}{V} \tau\right)
$$

By applying Equations (30) $\left(\tau_{\max } \rightarrow \infty\right)$ and (34), we get for $\bar{\tau}_{C r}$ :

$$
\bar{\tau}_{C r}=\frac{V}{\dot{V}}\left[\exp \left(-\frac{\dot{V}}{V} \tau_{\text {Diss }}\right)\left(-\frac{\dot{V}}{V} \tau_{\text {Diss }}-1\right)+1\right]+\tau_{\text {Diss }} \exp \left(-\frac{\dot{V}}{V} \tau_{\text {Diss }}\right)
$$

and for $\bar{\tau}_{c r}{ }^{\prime}$, using Equations (32 and 34), we have

$$
\bar{\tau}_{c r}=\frac{\frac{V}{\dot{V}}\left[\exp \left(-\frac{\dot{V}}{V} \tau_{\text {Diss }}\right)\left(-\frac{\dot{V}}{V} \tau_{\text {Diss }}-1\right)+1\right]}{1-\exp \left(-\frac{\dot{V}}{V} \tau_{\text {Diss }}\right)}
$$

Because $\tau_{\text {max }} \rightarrow \infty$ for ideal mixer, the inequality $\tau_{\text {Diss }} \prec \tau_{\max }$ is always valid when using Equations (33) to (36). The polynomial expressions for the melter space filling by glass can be used as an alternative to rigorous mathematical modeling of the glass flow.

Calculation conditions and results

The input values for the reference case, including the appropriate temperature functions, are summarized in Table I.

The average residence time of melt in the melter was received from mathematical modeling of the HLW melter. Another purpose of modeling was a verification of the assumption that the melter behaves almost as an ideal mixer. Crystals with the input concentration $C_{i n}=110 \mathrm{~kg} \mathrm{~m}^{-3}$ were charged into melter using the complete mathematical model. Crystal distribution procedure was applied using the assumption that $\dot{a}=0$ (crystals of constant size). The growth of the spinel crystal concentration in the melter could be fit with a polynomial function (see Figure 1)

$$
C=1.458+4.683 \times 10^{-4} \tau-9.322 \times 10^{-10} \tau^{2}+9.029 \times 10^{-16} \tau^{3}-3.430 \times 10^{-22} \tau^{4}
$$

with the estimated value of $\tau_{\max }\left(C \rightarrow C_{\infty}\right) 250 \mathrm{~h}$. 
Table I. Input values for the reference case

\begin{tabular}{|c|c|c|c|}
\hline Temperature & 1104 & ${ }^{\circ} \mathrm{C}$ & \\
\hline Temperature of liquidus & 1078 & ${ }^{\circ} \mathrm{C}$ & \\
\hline Glass density & 2437 & $\mathrm{~kg} \cdot \mathrm{m}^{-3}$ & $\rho_{1}=2722.7-0.2077 * T ; T$ in $\mathrm{K}$ \\
\hline Spinel density & 5140 & $\mathrm{~kg} \cdot \mathrm{m}^{-3}$ & \\
\hline $\begin{array}{l}\text { Input concentration of } \\
\text { spinel }\end{array}$ & 110 & $\mathrm{~kg} \cdot \mathrm{m}^{-3}$ & \\
\hline $\begin{array}{l}\text { Concentration of spinel } \\
\text { in the sludge layer }\end{array}$ & 822 & $\mathrm{~kg} \cdot \mathrm{m}^{-3}$ & \\
\hline Initial size of crystals & $1 \times 10^{-6}$ & $\mathrm{~m}$ & \\
\hline Critical size of crystals & $6.25 \times 10^{-8}$ & $\mathrm{~m}$ & \\
\hline Mass transfer coefficient & $2.51 \times 10^{-9}$ & $\mathrm{~m} \cdot \mathrm{s}^{-1}$ & $k_{H}=0.1777 * \exp (-24891 / T)$ \\
\hline Settling surface & 1.28 & $\mathrm{~m}^{2}$ & \\
\hline Melting space volume & 1 & $\mathrm{~m}^{3}$ & \\
\hline Nucleation space volume & 0 & $\mathrm{~m}^{3}$ & \\
\hline Equilibrium & $-3.21 \times 10^{-3}$ & $\mathrm{~m}^{3} \mathrm{~m}^{-3}$ & $C_{0}=0.004334 *(1-\exp (5110.7 *(1 / T-$ \\
\hline $\begin{array}{l}\text { concentration of spinel } \\
\text { Volume output }\end{array}$ & $5.13 \times 10^{-6}$ & $m^{3} s^{-1}$ & \\
\hline Glass viscosity & 7.55 & $\mathrm{Pas}$ & \\
\hline Nucleation density & $2.77 \times 10^{8}$ & $\mathrm{~m}^{-3}$ & $I=\exp \left(\left(-0.010823^{*} T\right)+13.622\right) * 1 \times 10^{9}$ \\
\hline $\begin{array}{l}\text { Average residence time } \\
\text { of glass in HLW }\end{array}$ & $1.9 \times 10^{5}$ & $\mathrm{~s}$ & \\
\hline
\end{tabular}

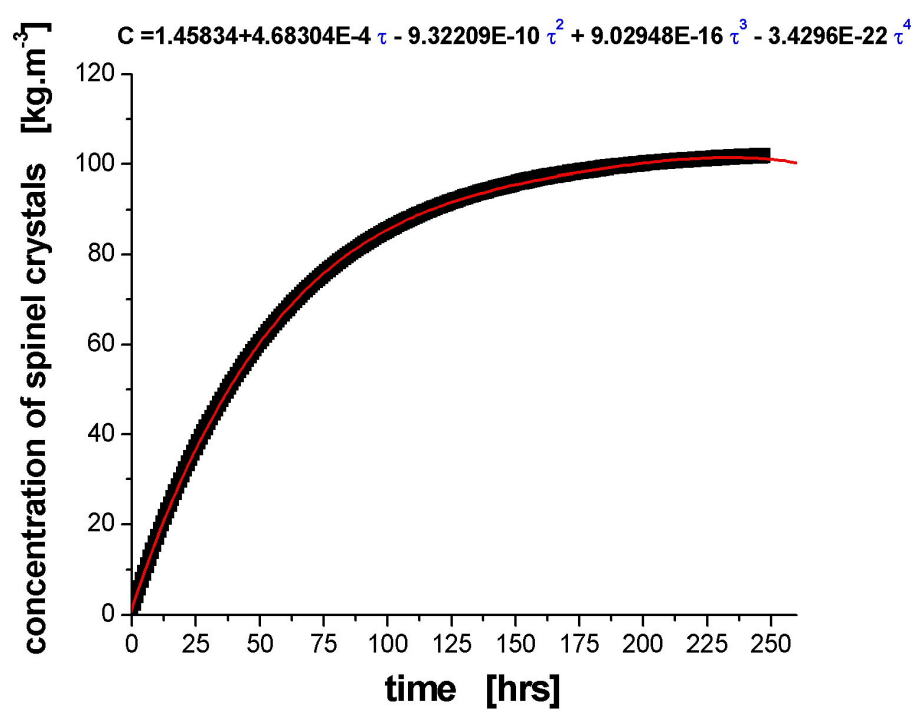

Figure 1. Filling of the HLW glass melter by new melt: a result of mathematical modeling ( $C$ is the mass concentration of crystals of constant size and identical density as the melt)

The time derivative of Equation (37) is

$$
\frac{d C}{d \tau}=4.683 \times 10^{-4}-1.864 \times 10^{-9} \tau+2.709 \times 10^{-15} \tau^{2}-1.372 \times 10^{-21} \tau^{3}
$$


Equation (38) expresses the crystal concentration distribution in glass according to glass residence times. Taking into account that $\int_{0}^{\tau_{\max }} f(\tau) d \tau=1$, and $\tau_{\max }=250 \mathrm{~h}$, the probability density function derived from Equation (38) has the form

$$
f(\tau)=4.683 \times 10^{-6}-1.864 \times 10^{-11} \tau+2.709 \times 10^{-17} \tau^{2}-1.372 \times 10^{-23} \tau^{3}
$$

As $\bar{\tau}$ is given by the expression $\int_{0}^{\tau_{\max }} f(\tau) \tau d \tau$, the value of $\quad \bar{\tau}$ was calculated using Equation (39) obtaining $\bar{\tau}=190228 \mathrm{~s}$. The mean residence time, given by the expression $V / \dot{V}$, was $194932 \mathrm{~s}$. The coincidence of these values confirms the assumption that the melter behaves as an ideal mixer.

Considering Equations (30) and (39), the value of $\bar{\tau}_{c r}$ can be calculated from the following equation:

$$
\begin{gathered}
\bar{\tau}_{c r}=2.342 \times 10^{-6} \tau_{d i s s}^{2}-6.213 \times 10^{-12} \tau_{\text {diss }}^{3}+6.773 \times 10^{-18} \tau_{\text {diss }}^{4}-2.744 \times 10^{-24} \tau_{d i s s}^{5}+ \\
+\tau_{\text {diss }}\left\langle 4.683 \times 10^{-6}\left(\tau_{\max }-\tau_{\text {diss }}\right)-9.32 \times 10^{-12}\left(\tau_{\max }^{2}-\tau_{\text {diss }}^{2}\right)+\right. \\
\left.+9.03 \times 10^{-18}\left(\tau_{\max }^{3}-\tau_{\text {diss }}^{3}\right)-3.43 \times 10^{-24}\left(\tau_{\max }^{4}-\tau_{\text {diss }}^{4}\right)\right\rangle
\end{gathered}
$$

Taking into account Equation (32), the following expression is at disposal for calculateling $\bar{\tau}_{c r}^{\prime}$ :

$$
\bar{\tau}_{c r}^{\prime}=\frac{2.342 \times 10^{-6} \tau_{d i s s}^{2}}{I}-\frac{6.213 \times 10^{-12} \tau_{\text {diss }}^{3}}{I}+\frac{6.772 \times 10^{-18} \tau_{\text {diss }}^{4}}{I}-\frac{2.744 \times 10^{-24} \tau_{\text {diss }}^{5}}{I}
$$

where $I=\int_{0}^{\tau_{\text {diss }}} f(\tau) d \tau$ is given by

$$
I=4.683 \times 10^{-6} \tau_{\text {diss }}-9.32 \times 10^{-12} \tau_{\text {diss }}^{2}+9.03 \times 10^{-18} \tau_{\text {diss }}^{3}-3.43 \times 10^{-24} \tau_{\text {diss }}^{4}
$$

Figures 2 to 6 summarize the main results of the parametric study. Figures 2 to 6 reveal the impacts of the initial size of crystals entering from the cold cap, the initial crystal concentration, the temperature, the liquidus temperature, and mass transfer coefficient on the thickness of the sludge layer after one year of melter operation.

As is obvious from the Figure 2, the crystal layer thickness grows steeply with the increasing size of entering crystals. This growth is brought about by the simultaneous increase of the average size of crystals and their stationary concentration, $C_{\infty}$, in the melter. The layer thickness grows only slowly with $C_{i n}$ because the average crystal size, $\bar{a}$, decreases (see Figure 3 ) while $C_{\infty}$ grows. 


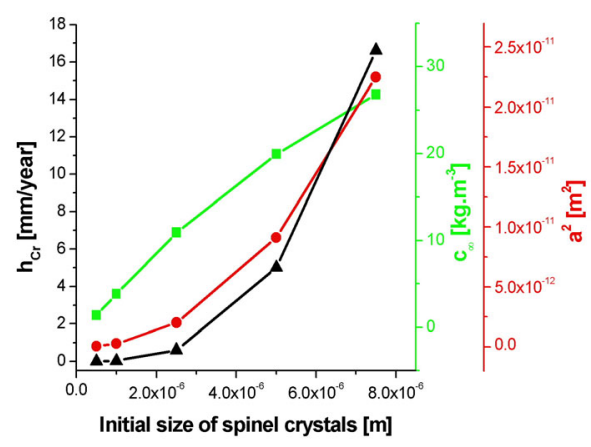

Figure 2. The crystal layer thickness after one year of the melter operation $\left(h_{C r}\right)$, the square of the average crystal size $\left(\bar{a}^{2}\right)$, and the stationary crystal concentration in the melter $\left(C_{\infty}\right)$ versus the initial size of spinel crystals

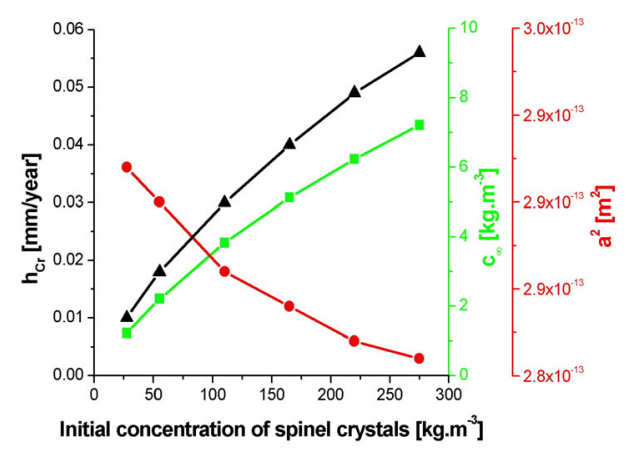

Figure 3. $h_{C r}, \bar{a}^{2}$, and $C_{\infty}$ versus the initial concentration of spinel crystals in the cold cap

The impact of temperature on crystal settling balances the influence of growing glass viscosity at low temperatures with faster crystal dissolution at higher temperatures. The layer acquires its maximum thickness at temperatures about $100^{\circ} \mathrm{C}$ below the liquidus temperature. This can bee seen in Figure 4 . The increasing liquidus temperature inhibits crystal dissolution and therefore supports crystal settling as is clear from the increasing layer thickness in Figure 5. A similar layer growth, brought about by simultaneous increase of both $C_{\infty}$ and $\bar{a}$ with decreasing mass transfer coefficient, is seen in Figure 6.

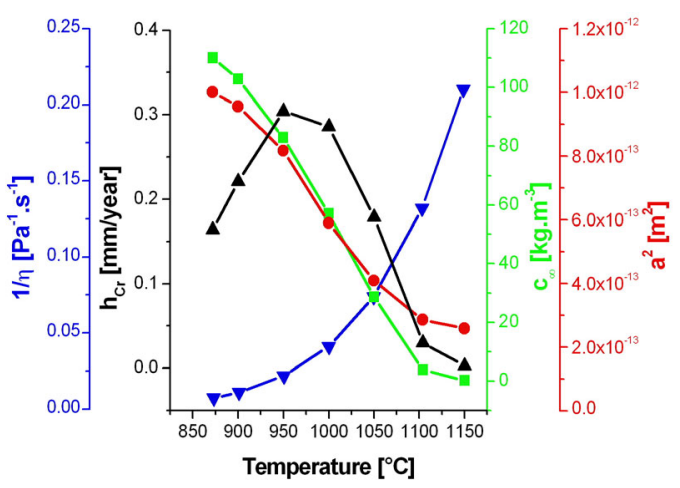

Figure 4. $h_{C r}, \bar{a}^{2}$, the inverse viscosity $(1 / \eta)$, and $C_{\infty}$ versus the average melt temperature

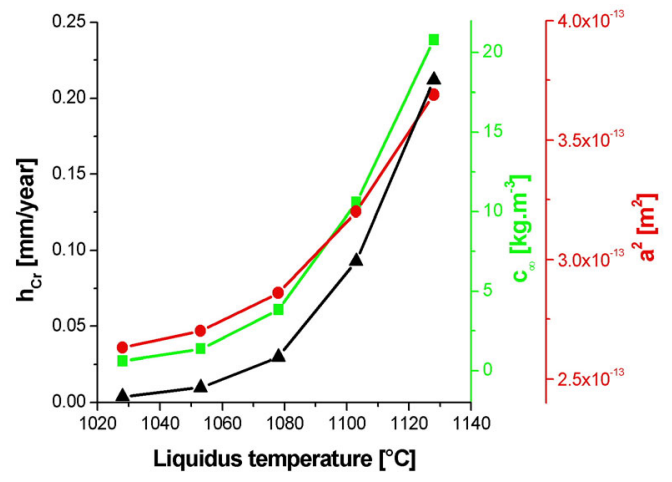

Figure 5. $h_{C r}, \bar{a}^{2}$, and $C_{\infty}$ versus $T_{L}$

The results of the ideal mixer were compared with the complete mathematical model of spinel settling to find the degree of the simplified model applicability. In the reference case, the results were almost identical. While the layer thickness after one year melter operation amounted $38 \mu \mathrm{m}$ in the complete model, the ideal mixer model provided $32 \mu \mathrm{m}$. However, the layer thickness tendencies have shown some differences between both models when varying mentioned parameters. The layer thickness dependence on the initial size of crystal was about 2.5 times steeper in the simplified model, and the dependence on the average temperature was about twice as steep. The layer thickness dependence on the initial crystal concentration, $C_{i n}$, was almost identical in both models. 


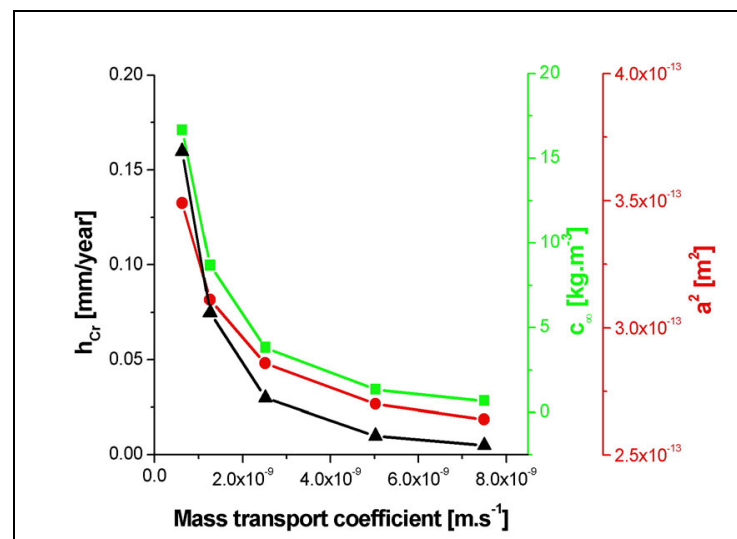

Figure 6. $h_{C r}, \bar{a}^{2}$, and $C_{\infty}$ versus the mass transfer coefficient
Despite these differences, the simplified ideal mixer model appears useful for estimating the trends of melter behavior when large numbers of layer thickness calculations are needed. The results of the ideal mixer model can be used as initial values in the complete model. This application allows an appreciable shortening of the calculation time of the complete model.

\section{$\underline{\text { References }}$}

1. J. Matyáš, J. Kloužek, L. Němec, and M. Trochta. 2001. "Spinel settling in HLW melters," ICEM'01 The 8th International Conference On Radioactive Waste Management and Environmental Remediation, Bruges, Belgium. 